\title{
High-precision laser ablation inductively coupled plasma mass spectrometry determination of trace elements in geological glasses by internal standardization
}

\author{
Aline Celuppi Wegner ${ }^{1 *}$ (D), Felipe Padilha Leitzke' (D), Carla Cristine Porcher ${ }^{1}$ (D), \\ Rommulo Vieira Conceição' (1), Marcia Elisa Boscato Gomes' (D), Daniel Grings Cedeño' (D, \\ Marcio Roberto Wilbert de Souza' (D)
}

\begin{abstract}
The analysis of trace elements (TE) in geological materials is a valuable tool to understand geological processes, including studies in geochemistry and petrology. Among the methods applied to determine TE, Laser Ablation Inductively Coupled Plasma Mass Spectrometry (LA-ICP-MS) detects TE contents in the $\mu \mathrm{g} / \mathrm{g}$ and $\mathrm{ng} / \mathrm{g}$ range. The aim of this paper is to validate, at Laboratório de Geologia Isotópica (LGI) - Centro de Estudos em Petrologia e Geoquímica/Universidade Federal do Rio Grande do Sul (CPGq/UFRGS), a high-precision method for LA-ICP-MS analyses of TE in geological materials. Samples used in this work were reference Max-Planck-Institut für Chemie - Dingwell (MPI-DING) glasses. The method is used in tandem with the Electron Probe Microanalyzer - Wavelength Dispersive X-ray Spectrometer (EPMA-WDS) technique to determine the major and minor elements of the samples and check for homogeneity. Analyses were conducted in a Thermo ${ }^{\circledast}$ Element2 Inductively Coupled Mass Spectrometer (ICP-MS) coupled to a New Wave Research ${ }^{\circledast}$ Neodymium-Doped Yttrium Aluminum Garnet (Nd:YAG) $\left(213 \mathrm{~nm}\right.$ ) laser ablation system. ${ }^{43} \mathrm{Ca}$ and ${ }^{29} \mathrm{Si}$ were used as internal standards (IS). Glitter ${ }^{\circledR}$ software and in-house spreadsheets were utilized for reduction treatments. The results using ${ }^{29} \mathrm{Si}$ as IS present a high degree of fractionation errors compared to the results using ${ }^{43} \mathrm{Ca}$. Uncertainties caused by matrix interferences and fractionation effects can be corrected applying a correction factor. The obtained results demonstrate an effective recovery of TE content for the analyzed reference materials. Moreover, these silicate glasses proved to be robust to create an internal database of matrix matching standards in routine silicate analyses.
\end{abstract}

KEYWORDS: analytical method; geochemistry; laser ablation inductively coupled plasma mass spectrometer; mass spectrometry; trace elements.

\section{INTRODUCTION}

For geochemical purposes, trace elements are those present in concentrations lower than $1000 \mu \mathrm{g} / \mathrm{g}$ in a geological material, such as mineral phases, volcanic glasses, or whole rock (Gill 2014). Their low concentrations in nature occur because most of them, having heavy atomic masses, were not extensively produced during nucleosynthesis, usually having low cosmochemical abundances (Palme and O’Neill 2014). Moreover, because they generally have large ionic radii, such as the Large Ion Lithophile Elements (LILE), or a high valence

\section{Supplementary material}

Supplementary data associated with this article can be found in the online version: Supplementary Table A1.

${ }^{1}$ Universidade Federal do Rio Grande do Sul - Porto Alegre (RS), Brazil E-mails: alineceluppi@gmail.com, felipe.leitzke@gmail.com, carla. porcher@ufrgs.br, rommulo.conceicao@ufrgs.br, marcia.boscato@ufrgs. br, daniel.gringscedeno@gmail.com.br,_rwsmarcio@gmail.com

${ }^{*}$ Corresponding author. state, such as the Rare-Earth Elements (REE) and the Highfield Strength Elements (HFSE), they do not constitute the stoichiometric compounds of major rock forming minerals (White 2013). Obviously, the concept of trace element will be relative to the geochemical system of interest, being a classical example that of $\mathrm{K}$, which is a trace element in the Earth's mantle (peridotite) but a major element in crustal rocks, such as granites. Despite their rarity, the study of trace elements can provide crucial information about the origin and evolution of geological materials, mainly because their variation is by orders of magnitude larger than the one observed in major elements, and their behavior is independent of the phase relationships between the minerals that crystallize from magmas, being used to track geological processes that are not recorded by major elements (e.g., Kelemen et al. 1993, Münker 2000). With the advent of mass spectrometry, especially coupled to techniques of microanalyses, the study of trace elements in geological materials has become a fundamental part of any geochemical or petrological study. For example, trace elements have long been successfully applied to constrain tectonic settings and petrogenesis of a given geological unit (e.g., Pearce et al. 1984, Whalen et al. 1987, Maniar and Piccoli 
1989, Prowatke and Klemme 2006), in mineral exploration and the origin of ore deposits (e.g., Pearce and Gale 1977, Hutchinson and McDonald 2008, Reich et al. 2017), or even to constrain large-scale planetary formation and differentiation processes (e.g., Pfänder et al. 2007, Leitzke et al. 2017, Thiemens et al. 2019).

Among the commonly used methods for determining trace element abundance in minerals and rocks are the Secondary Ion Mass Spectrometry (SIMS) and the Laser Ablation Inductively Coupled Plasma Mass Spectrometry (LA-ICP-MS). Both methods allow for trace determination to sub-trace concentrations in situ with a laser spot size of 10 to $100 \mu \mathrm{m}^{2}$ and, due to their lower limits of detection, are more appropriate than Electron Probe Micro-Analyzer (EPMA) to determine trace element contents or even the X-Ray Fluorescence (XRF) technique which, despite not performing in situ analysis, is able to determine a few trace elements (Stalder et al.2001). The determination of trace elements by LA-ICP-MS is a well-established and documented technique. Among the advantages of using this technique, the following can be mentioned: MS high sensitivity, possibility of performing multi-element analysis of trace elements, ease of use and versatility in sample introduction (e.g., nebulization, laser ablation), ability to perform an in situ analysis of mineral phases and microanalysis, enables accurate, direct, and rapid analysis, high temperatures in the plasma source, ensuring desolvation and ionization of the sample molecules (Becker and Dietze 1998, Sato and Kawashita 2002, Thomas 2003, Orihashi and Hirata 2003, Sylvester and Jackson 2016). Despite that, the technique also has some downsides, including the destruction of the ablated sample and the chemical reactions between the high-energy ions formed in the plasma source, which can cause interference due to fractionation effects and isobaric interferences (Sato and Kawashita 2002, Thomas 2003, Becker 2007). When compared to other techniques of analysis commonly used to determine trace elements in geological materials (e.g., EPMA, XRF), the main advantage is the high sensitivity of the LA-ICP-MS, detecting concentrations in the order of $\mathrm{ng} / \mathrm{g}$, while more traditional techniques detect a maximum of tens of $\mu \mathrm{g} / \mathrm{g}$ in trace element determinations. In this case, only the most abundant trace elements in the sample will be determined with less-sensitive techniques, excluding information about trace elements in small abundance.

Therefore, the main goal of this study was to validate a method for high-precision microanalyses (50 to $100 \mu \mathrm{m}$ ) of trace elements in the range of $\mathrm{ppm}(\mu \mathrm{g} / \mathrm{g})$ to $\mathrm{ppb}(\mathrm{ng} / \mathrm{g})$ in geological samples by LA-ICP-MS at the Laboratório de Geologia Isotópica (LGI) of Universidade Federal do Rio Grande do Sul (UFRGS), Brazil. This study also aimed to compare the data obtained at the LGI for major elements and homogeneity of the geological reference glasses used to validate this method with literature data, determine the best conditions for laser ablation analysis in geological glasses, determine spot size limits for laser ablation analysis, and determine detection limits for trace element determinations. The results of this work can be applied to the analysis of geological glasses obtained from whole rock samples, can be used to determine the best conditions of the equipment for future analysis in varied materials (e.g., mineral phases, corals), and to validate the reference materials analyzed to be used as external standards among National Institute of Standards and Technology - Standard Reference Materials (NIST-SRM) in future analysis with the same methodology. The study was carried out using several analytical techniques commonly used in the investigation of geological materials, including EPMA, Scanning Electron Microscope (SEM), and LA-ICP-MS. Among the dataset of trace elements chosen to be analyzed are those most relevant for geochemical applications, i.e., V, Cr, Ni, Cu, Zn, Rb, Sr, Y, Zr, Nb, Ba, La, Ce, Pr, Nd, Sm, Eu, Gd, Dy, Ho, Er, Yb, Lu, Hf, Ta, Th, and U.

\section{MATERIALS AND METHODS}

\section{Sample selection}

For this study, we selected a set of seven reference silicate glasses provided by the Max Planck Institut für Chemie (MPIDING). These glasses comprise a large compositional range observed in nature, from mafic to silicic rocks, and are well described in the literature (Jochum et al. 2005), enabling not only direct comparison and validation of the method developed, as well as the use of these samples as future matrix-match external reference materials for LA-ICP-MS analyses. Among the selected samples, there are two basalts from the Kilauea (KL2G) and Mauna Loa (ML3B-G) volcanoes in Hawaii, one andesite from the St. Helen volcano (StHs6/80-G), two komatiites (GOR128-G and GOR132-G) from the Gorgona Island, one rhyolite (ATHO-G) from Iceland, and a quartz diorite (T1G) from the Italian Alps. Samples from the silicate glasses used in this study were produced at the MPI (Mainz), without changing the original composition, by direct fusion and stirring of rock powders in the range of $1400-1600^{\circ} \mathrm{C}$ in a platinum crucible (Bagdassarov and Dingwell 1992, Stebbins et al. 1995, Jochum et al. 2000).

\section{EPMA-WDS and SEM}

Major and minor element ( $\mathrm{Na}, \mathrm{Al}, \mathrm{Si}, \mathrm{Mg}, \mathrm{K}, \mathrm{Ca}, \mathrm{Ti}, \mathrm{Mn}$, $\mathrm{Fe}$, and $\mathrm{Cr}$ ) concentrations were determined using a Cameca SXFive EPMA (Instituto de Geociências - UFRGS) in WDS mode, employing $15 \mathrm{kV}$ acceleration voltage and $15 \mathrm{nA}$ beam current with a count integration time of $20 \mathrm{~s}$ at the peak and $10 \mathrm{~s}$ at the background. Each sample of silicate glass was measured by randomly allocating ten spots with an electron beam defocused to $5 \mu \mathrm{m}$, a spot-size that showed a stable signal during the analyses, excluding any possibility of thermal migration. Peak to background calibrations were performed in Albite ( $\mathrm{Na}$ ), Sanidine (Al, Si and K), Diopside (Ca and $\mathrm{Mg}$ ), Rutile ( $\mathrm{Ti}$ ), Rhodonite ( $\mathrm{Mn})$, Hematite $(\mathrm{Fe})$, and Chromite (Cr). To verify the homogeneity of the glass standards, backscattered electron (BSE) images were obtained in a SEM. The equipment used was a Jeol 6610-LV at the LGI/UFRGS. Samples were coated with a single carbon layer and analyzed with accelerating voltage of $15 \mathrm{kV}$, working distance of $10 \mathrm{~mm}$, and spot size of $65 \mu \mathrm{m}$. 


\section{LA-ICP-MS}

The trace element analysis was performed on a Thermo Fisher ${ }^{\circledR}$ Element 2 Sector Field ICP-MS coupled to a New Wave Research ${ }^{\circledR}$ high performance Nd: YAG deep UV (213 nm) laser ablation system. To choose the best frequency, energy, and spot size for maximizing sensitivity and precision during the analyses, we performed tests on the T1-G sample with a laser spot size ranging from 4 to $100 \mu \mathrm{m}$ (Fig. 1). Below $30 \mu \mathrm{m}$, the variation of the mean value measured is higher than one order of magnitude between each spot. The ICP-MS-measured signal shows uncertainty values above the mean value of the measurement itself, below $15 \mu \mathrm{m}$ and at least more than $50 \%$ of the mean value from 15 to $30 \mu \mathrm{m}$. Above $40 \mu \mathrm{m}$, the signal reaches a stable plateau and a spot size larger than this could be potentially used for the analyses, given that values are similar or at least not varying by more than one order of magnitude for the tested analytes, with overall uncertainty below $25 \%$ of the mean value. This spot size criterion is not so straightforward and universally applicable, because the sensitivity will depend on the settings of the ICP-MS during the analyses (Tab. 1) and the concentration of the element in the sample. Nevertheless, based on these preliminary results, and the fact that there was not a size limit for the glass samples, we chose to use a $100 \mu \mathrm{m}$ spot size and frequency of $20 \mathrm{~Hz}$ as standard settings, with $100 \%$ output power to obtain a minor deviation from the literature concentration (Gaboardi and Humayun 2009).

After achieving optimal laser ablation conditions in the silicate glasses, the best sensitivity in the ICP-MS analysis (Tab. 1) was reached after a series of adjustments usually called tuning performance enhancement (Thermo Finnigan Scientific 2005). These focus on adjusting the better count rates for the masses of ${ }^{7} \mathrm{Li},{ }^{115} \mathrm{In}$, and ${ }^{238} \mathrm{U}$ using a tune solution (Tune-up Solution Element, 5\% HNO3, Thermo Scientific, Bremen, Germany) with a quartz double pass spray chamber and a concentric nebulizer and only Argonium as sample gas (Argon Pure Liquid 99.9\%, Air Products, Guaíba, Brazil). After that, tuning of the ICP-MS for laser ablation was also performed on the NIST-612 to maximize sensitivity, count rate, and detection limit with the laser (Tab. 2), by monitoring the count rates for ${ }^{238} \mathrm{U},{ }^{232} \mathrm{Th}$, and oxygen production rate. To optimize the signal, a take-up ablation time of 5 seconds was used on the sample/standard before starting the analysis in the ICP-MS. This ensures that the entire system is purged with the ablation gas and set with the mixture of the sample and sample gas, certifying there is no "gap" time in the analysis. Sample chamber was emptied and flushed with Helium gas (compressed, purity of 99.5 - 100\%, White Martins/Praxair Inc., Rio de Janeiro, Brazil) between each sample analysis to
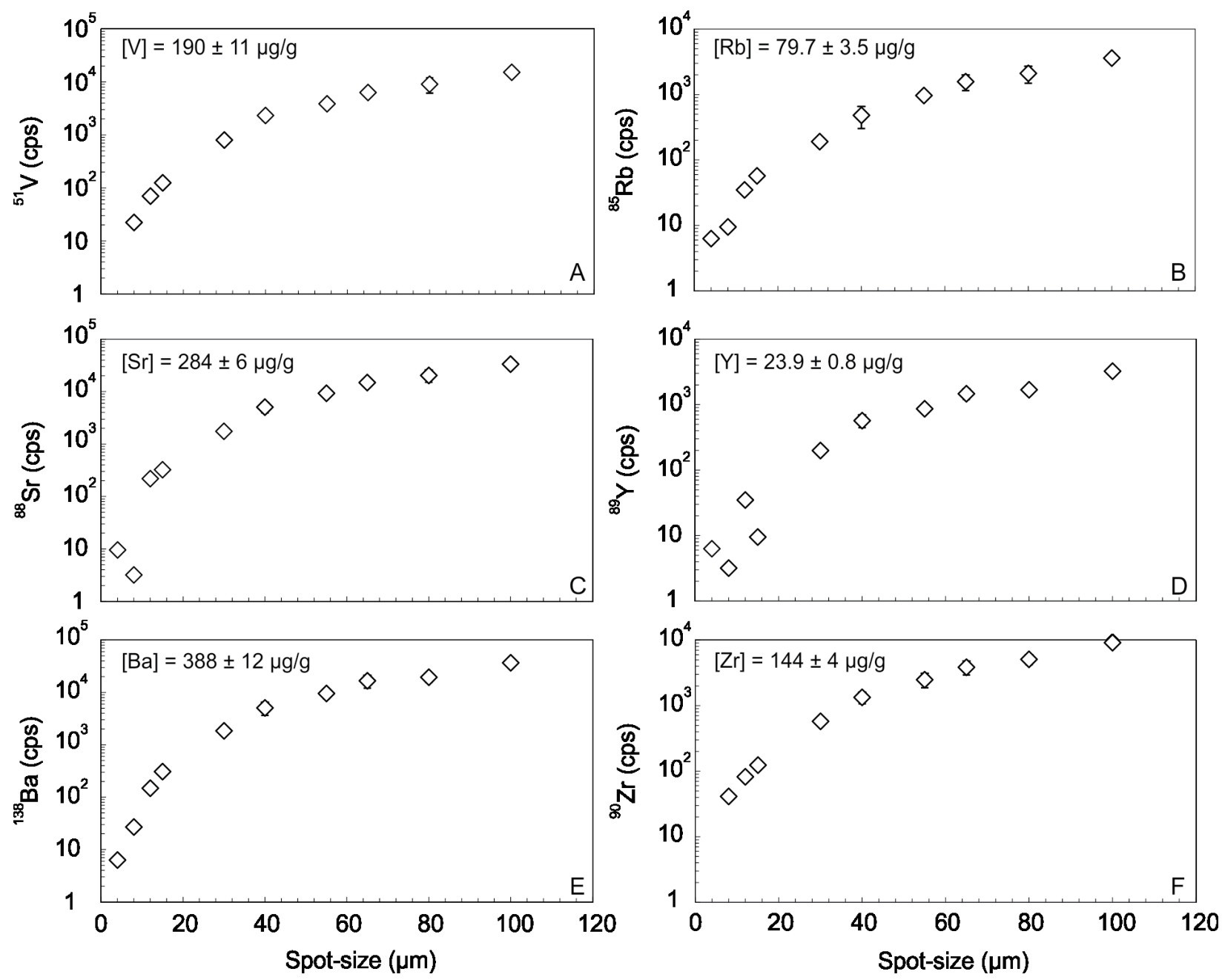

Figure 1. Comparison between laser spot-size and ICP-MS cps for selected analytes at the T1-G quartz diorite glass: (A) ${ }^{51} \mathrm{~V}$, (B) ${ }^{85} \mathrm{Rb}$, (C) ${ }^{88} \mathrm{Sr},(\mathrm{D}){ }^{89} \mathrm{Y},(\mathrm{E}){ }^{138} \mathrm{Ba},(\mathrm{F}){ }^{90} \mathrm{Zr}$. Error bars are two standard deviations $(2 \sigma)$ of the mean value and only plotted above $40 \mu \mathrm{m}$. When not shown, error bars are smaller than the symbol. 
Braz. J. Geol. (2021), 51(3): e20210018

Table 1. Operating conditions and instrument settings

\begin{tabular}{lccc}
\hline ICP-MS & & & Laser ablation \\
\hline Magnetic Sector Field ICP- & Finnigan Element2 from Thermo & Model & UP213 Nd:YAG New Wave \\
MS Model & Fischer Scientific & \\
Forward Power & $1,300 \mathrm{~W}$ & Wavelength & $213 \mathrm{~nm}$ \\
Reflected Power & $3 \mathrm{~W}$ & Max. output energy & $100 \%$ \\
Cool Gas flow rate (Ar) & $1.5 \mathrm{~L} / \mathrm{min}$ & Pulse width & $4 \mathrm{~ns}$ \\
Auxiliary Gas flow rate (Ar) & $0.86 \mathrm{~L} / \mathrm{min}$ & Energy density & $100 \mathrm{~mJ}$ \\
Ablation Cell gas flow (He) & $0.5 \mathrm{~L} / \mathrm{min}$ & Focus & Fixed at sample surface \\
Injector & Injektor quartz ICP II Ø & Repetition rate & $20 \mathrm{~Hz}$ \\
Sample Cone & $1,75 \mathrm{~mm}$ & Spot size & $100 \mu \mathrm{m}$ \\
Skimmer Cone & Ni with $1.15 \mathrm{~mm}$ orifice & Ablation cell & $\varnothing 2.54 \mathrm{~cm}$ \\
Runs & Ni with $0.6 \mathrm{~mm}$ orifice & Sample time & $0,075 \mathrm{~s}$ \\
Passes & 3 & Sample per peak & 35 \\
Take-up time & 2 & Passes & 1 \\
Magnet mass & $5 \mathrm{~s}$ & Depth/pass & $30 \mu \mathrm{m} / \mathrm{s}$ \\
Dwell time & 235.043 & Sampling scheme & spot \\
Mass Window & $0.285 \mathrm{~s}$ & & \\
Acquisition Mode & 150 & & \\
\hline
\end{tabular}

Table 2. LA-ICP-MS trace element sensitivities and detection limit (DL) on MPI-DING glasses.

\begin{tabular}{|c|c|c|c|c|}
\hline Element & $\begin{array}{c}\text { Mass } \\
\text { analyzed }\end{array}$ & $\begin{array}{l}\text { Avg. Sensitivity } \\
\text { (cps per ug } \text { g }^{-1} \text { ) }\end{array}$ & \pm & $\begin{array}{c}\text { Detection } \\
\text { limit } \\
\left(\mathbf{u g ~ g}^{-1}\right)\end{array}$ \\
\hline $\mathrm{V}$ & 51 & 6,391 & 1,823 & 0.01 \\
\hline $\mathrm{Cr}$ & 53 & 531 & 161 & 0.2 \\
\hline $\mathrm{Ni}$ & 62 & 197 & 42 & 0.6 \\
\hline $\mathrm{Cu}$ & 63 & 3,612 & 1,352 & 0.02 \\
\hline $\mathrm{Zn}$ & 66 & 636 & 209 & 0.08 \\
\hline $\mathrm{Rb}$ & 85 & 8,337 & 1,905 & 0.01 \\
\hline $\mathrm{Sr}$ & 88 & 9,137 & 1,789 & 0.01 \\
\hline $\mathrm{Y}$ & 89 & 9,858 & 1,529 & 0.006 \\
\hline $\mathrm{Zr}$ & 90 & 4,837 & 810 & 0.01 \\
\hline $\mathrm{Nb}$ & 93 & 8,748 & 766 & 0.006 \\
\hline $\mathrm{Ba}$ & 138 & 7,501 & 1,597 & 0.008 \\
\hline $\mathrm{La}$ & 139 & 12,212 & 4,429 & 0.004 \\
\hline $\mathrm{Ce}$ & 140 & 12,312 & 2,675 & 0.004 \\
\hline $\operatorname{Pr}$ & 141 & 13,351 & 1,035 & 0.005 \\
\hline $\mathrm{Nd}$ & 146 & 2,163 & 354 & 0.01 \\
\hline $\mathrm{Sm}$ & 152 & 2,460 & 446 & 0.01 \\
\hline $\mathrm{Eu}$ & 153 & 6,397 & 1,214 & 0.007 \\
\hline Gd & 160 & 1,888 & 313 & 0.02 \\
\hline Dy & 161 & 1,841 & 365 & 0.02 \\
\hline Ho & 165 & 8,840 & 1,680 & 0.006 \\
\hline $\mathrm{Er}$ & 166 & 2,949 & 531 & 0.01 \\
\hline $\mathrm{Yb}$ & 172 & 1,687 & 315 & 0.03 \\
\hline $\mathrm{Lu}$ & 175 & 7,170 & 1,394 & 0.007 \\
\hline Hf & 178 & 3,887 & 1,275 & 0.01 \\
\hline $\mathrm{Ta}$ & 181 & 11,761 & 1,178 & 0.005 \\
\hline Th & 232 & 13,948 & 5,872 & 0.001 \\
\hline $\mathrm{U}$ & 238 & 13,325 & 2,235 & 0.004 \\
\hline
\end{tabular}

prevent the formation of oxide compounds, which were monitored by the oxide production rate based on the count rates for the $\mathrm{Th} / \mathrm{ThO}^{+}$ratio. We performed five analysis runs, performing around 10 analyzes for each MP-DING glass in each run. The following isotopes were monitored during analyses in low resolution, albeit not all of them yielded meaningful results for several reasons and a preferred one was selected for each element: ${ }^{47} \mathrm{Ti},{ }^{50} \mathrm{Ti},{ }^{51} \mathrm{~V},{ }^{52} \mathrm{Cr},{ }^{53} \mathrm{Cr},{ }^{55} \mathrm{Mn},{ }^{60} \mathrm{Ni}$, ${ }^{62} \mathrm{Ni}$, ${ }^{63} \mathrm{Cu},{ }^{65} \mathrm{Cu},{ }^{66} \mathrm{Zn},{ }^{68} \mathrm{Zn},{ }^{85} \mathrm{Rb},{ }^{88} \mathrm{Sr},{ }^{89} \mathrm{Y},{ }^{90} \mathrm{Zr},{ }^{91} \mathrm{Zr},{ }^{92} \mathrm{Zr},{ }^{93} \mathrm{Nb},{ }^{137} \mathrm{Ba}$, ${ }^{138} \mathrm{Ba},{ }^{139} \mathrm{La},{ }^{140} \mathrm{Ce},{ }^{141} \mathrm{Pr},{ }^{146} \mathrm{Nd},{ }^{150} \mathrm{Nd},{ }^{147} \mathrm{Sm},{ }^{152} \mathrm{Sm},{ }^{154} \mathrm{Sm},{ }^{153} \mathrm{Eu}$, ${ }^{157} \mathrm{Gd},{ }^{160} \mathrm{Gd},{ }^{161} \mathrm{Dy},{ }^{163} \mathrm{Dy},{ }^{165} \mathrm{Ho},{ }^{166} \mathrm{Er},{ }^{168} \mathrm{Er},{ }^{170} \mathrm{Er},{ }^{172} \mathrm{Yb},{ }^{174} \mathrm{Yb}$, ${ }^{175} \mathrm{Lu},{ }^{174} \mathrm{Hf},{ }^{178} \mathrm{Hf},{ }^{180} \mathrm{Hf},{ }^{181} \mathrm{Ta},{ }^{232} \mathrm{Th},{ }^{235} \mathrm{U}$, ${ }^{238} \mathrm{U}$. Among all the isotopes measured in this study, the masses selected to quantify each element are listed in Table 2.

Considering the nature of the LA-ICP-MS technique, our results for trace element are based on the analysis of a specific isotope mass of that element, called analyte. Therefore, selecting an appropriate analyte for each mass for those elements that are not monoisotopic is an essential step. To do that, atomic masses were selected that presented the closest values to the preferred ones, i.e., having negligible isobaric interferences with the rest of the elements in the sample. This procedure is sample-specific, given that different sample compositions can show different amounts of interfering masses in the measured mass (Jenner and Arevalo Jr. 2016). There are several possible interferences for each elemental isotope chosen to be the analyte, and they are presented in a Table that can be found in the Supplementary Table A1.

Limits of detection on LA-ICP-MS analyses are a function of the amount of material extracted from the sample and introduced in the mass spectrometer, being, therefore, variable for each analysis (Longerich et al. 1996). To quantify the limit of detection for each mass, it is necessary to measure several samples with no analyte, which is normally 
done by acquiring data only with the gas flow to the ICP-MS, without firing the laser, i.e., equivalent to the machine background (e.g., Luo et al. 2007). Calculating the detection limit this way poses an issue because the machine background is normally extremely low in LA-ICP-MS, especially for heavy isotopes, unlike the values found when measuring solution blanks. Therefore, to avoid dealing with the non-gaussian distribution of the background values when there are only a few measurements, Poisson counting statistics is used and the detection limit (DL) for each analyte $(\mathrm{x})$ is determined by the Equation 1 (Dussubieux et al. 2016):

$D L_{X}=3.29 \cdot \sqrt{\mu_{B G x}} \cdot 1 / \sqrt{n}+2.71 / S_{x} \cdot D T_{x}$

Where:

$\mu_{B G x}=$ the mean value in counts per second (cps) of all background measurements multiplied by the dwell time $(D T)$; $n=$ the number of background measurements;

$S_{x}=$ the sensitivity, i.e., the signal detected per unit of concentration.

By applying Equation 1, we obtained the detection limit values raging from the lowest value of $0.001 \mu \mathrm{g} / \mathrm{g}$ for Th to the highest value of $0.6 \mu \mathrm{g} / \mathrm{g}$ for $\mathrm{Ni}$ (Tab. 2). The 2.71 factor is related to $5 \%$ of false positive results, which corresponds to a confidence level of $95 \%$ (Tanner 2010).

\section{Calibration strategy and data reduction}

Differences in ablation yield are a common issue in LA-ICP-MS analyses and are produced through transporting different amounts of sample material to the ICP-MS during the acquisition time with the laser on. These differences can arise not only from changes in laser ablation conditions (i.e., laser spot size, frequency, and energy), but also due to the different physicochemical properties of the samples, which will weakly or strongly absorb a particular laser wavelength causing extensive variation in the ablation yield (Kurosawa et al. 2002, Rege et al. 2008). Moreover, differences in the ionization potential, melting and boiling point, and, in turn, volatility of the chemical elements can cause elemental fractionation between the vapor and the solid phase during laser ablation, even when the rest of the conditions in the system are ideal (e.g., Fryer et al. 1995, Outridge et al. 1997, Chen 1999, Guillong et al. 2003). To overcome any issues with changes in the amount of material that is ablated, transported, and ionized in the ICP-MS, a correction factor is applied by using internal standardization. In this study, LA-ICP-MS data were calibrated and quantified by periodically combining (at the beginning and end) the ablation of an external standard (NIST-610/612 glasses) with an IS $\left({ }^{43} \mathrm{Ca}\right.$ or $\left.{ }^{29} \mathrm{Si}\right)$, that is, with an element of known concentration in the sample and standard (e.g., Rege et al. 2008). This procedure has been recognized to provide accurate analyses for many trace elements, even when using external standards without matrix matching (Jackson et al. 1992, Perkins et al. 1993, Eggins 2003, Wu et al. 2018). The choice of ${ }^{43} \mathrm{Ca}$ as IS fulfils the requirements established by Frick and Günther (2012), as follows: the element must be homogeneously distributed individually in the samples and in the reference material, must be present in sufficient concentration for determination both by LA-ICP-MS and an independent method (in our case, EPMA-WDS), and must have the same fractionation behavior as the analytes. We also chose to use ${ }^{29} \mathrm{Si}$ as an alternative IS in a second step of this work to compare the data obtained and have an alternative IS element if needed. It also fulfils the requirements as ${ }^{43} \mathrm{Ca}$ and was determined by EPMA-WDS. The choice of the NIST 610 and 612 glasses as external standards is justified because they have been used successfully and routinely to calibrate LA-ICP-MS trace element analyses of several geological materials, from strong UV-absorbing materials (e.g., titanite) to colorless, weak UV-absorbing materials, such as fluorite or silicate glasses (see Jackson et al. 1992, Rege et al. 2008). At the beginning and between the analyses, blank (background) values were recorded by flushing the carrier gas $(\mathrm{He})$ into the ICP-MS, without firing the laser, and these values were deducted from the laser signal values. IS standard normalized count rates were converted to concentrations using the count rates of spots carried out on the NIST 610 and 612 glasses as the external standard, using the preferred values from Jochum et al. (2011), and the methodology of Longerich et al. (1996), which is represented by the Equation 2 :

$[C]_{M}^{S}=[C]_{M}^{E S} \cdot(C R)_{M}^{S} /(C R)_{M}^{E S} \cdot\left[[C]_{M}^{I S} /(C R)_{M}^{I S} \cdot(C R)_{E S}^{I S} /[C]_{E S}^{I S}\right]$

Where:

$[C]=$ concentration;

$S=$ sample;

$M=$ mass (analyte);

$(\mathrm{CR})=$ count rate;

IS = internal standard (in our study, ${ }^{43} \mathrm{Ca}$ or ${ }^{29} \mathrm{Si}$ );

$E S$ = external standard (in our study, NIST SRM 610 and 612 glasses).

The data reduction in this work was conducted in two different ways. One dataset was reduced using in-house Microsoft ${ }^{\circledR}$ Excel (2007) spreadsheets tables applying the method of Longerich et al. (1996). A different dataset was obtained and treated with the Glitter ${ }^{\circledR}$ software (v 4.4) for data reduction of LA-ICP-MS (Griffin et al.2008). With this tool, the background measurement procedure changed, as the critical analysis of the data. The software allows measuring the background signal and the analytic signal in the same measurement. After completing the ICP-MS analysis, the signal can be reviewed and the background signal can be correctly separated from the analytical signal. Another advantage of using a reduction software is the ability to vary the IS element without the inconvenience having to manually enter the data to the chart. Thus, the data from a second round of analysis was reduced using both ${ }^{43} \mathrm{Ca}$ and ${ }^{29} \mathrm{Si}$ as IS. Therefore, we present trace element data in three groups, and use them to make a comparison, understand, and validate our measurements. 


\section{Data evaluation}

The critical evaluation of the data obtained is necessary since different sources of uncertainty can occur in LA-ICP-MS, such as fractionation effects, ion formation, transmission, and ablation behavior. These uncertainty sources are considered routine when proceeding with trace elements analysis with LA-ICP-MS, and have already been approached by several authors (e.g., Eggins et al. 1997, Chen 1999, Jochum et al. 2007, Jochum and Stoll 2008, Liu et al. 2008, Jenner and O'Neill 2012). To correct these factors of interference in this study, we used the Relative Sensitivity Factor (RSF), which can correct the negative effects, as well as issues regarding transportation efficiency, ablation yield, and detection of the elements (Willbold et al.2003, Jochum et al. 2007). According to Jochum et al. (2007), the RSF is defined as Equation 3:

$R S F=C_{E L, \text { uncorr }} / C_{E L, \text { true }}$

Where:

$C_{\mathrm{EL}, \text { uncorr }}=$ the uncorrected concentration of a given element, the experimental data obtained;

$C_{\mathrm{EL}, \text { true }}=$ the reference value of the concentration for the element in analysis, obtained as the average value of a given element in the literature.

With the RSF, we obtain the corrected value of the element under analysis, in $\mu \mathrm{g} / \mathrm{g}$ as $\mathrm{C}_{\mathrm{EL}}$, according to the Equation 4 :

$C_{E L}=C_{E L, \text { uncorr }} \times(1 / R S F)$

The RSF factor is an empirical value that is different for each element and can vary according to the operating conditions of the analysis. It also helps to understand the nature of the identified error. For differences up to $15 \%$ from the unity, it can be related to matrix effects and element fractionation between the external standard and the geological glass. A RSF ranging from 3 to $10 \%$ is accepted as common for daily work. When the major element composition of the external standard and the glasses are different, the RSF is around 5\% (Jochum et al. 2007). The RSF was applied in all data obtained in this study to identify the fractionation interferences and correct the values obtained. This factor can also help to understand if the interference is a negligible or significant fractionation product. In routine work, the proposal is to obtain the RSF of a reference material, identify the trace elements with high degree of fractionation, and use the correction factor in these elements only, as well as having standard reference glasses with good reproducibility during routine analysis.

\section{RESULTS}

\section{Major and minor element composition of the silicate glasses}

The major and minor element contents of the MPI-DING glasses in this study were obtained by EPMA-WDS and are shown in Table 3 and plotted on the TAS classification diagram (Bas et al. 1986) in Figure 2. The chart in Figure 3 shows the mean WDS values $(n=10)$ normalized by the standard concentration values of the reference materials of geological and environmental interest database (GeoREM) (Jochum et al. 2005). Major and minor elements show good concordance with the standard values, except for alkalis and manganese, which diverge in more than $10 \%$ in some samples. On the alkalis vs. silica diagram, all samples are classified as sub-alkaline or tholeiitic in composition, covering a range of $\mathrm{SiO}_{2}$ from 45 to $76 \mathrm{wt}$.\% from basalts to andesite, dacite and rhyolite. Overall, the glasses are homogeneous, with relative standard deviation values for major elements between ca. 0.1 and $4 \%$. The exceptions are the komatiite glasses, which, in the case of the GOR128-G, can show a variation of up to $30 \%$ in $\mathrm{MgO}$ and $\mathrm{CaO}, \mathrm{FeO}$ and $\mathrm{Al}_{2} \mathrm{O}_{3}$, related to the formation of quenched olivine crystals after rock fusion (Fig. 4A), as already reported in the literature for this reference material (Jochum and Stoll 2008). However, we have also found disseminated $\mathrm{Fe}-\mathrm{Cr}$ spinel crystals in the matrix (Figs. 4B-4D) of the GOR128-G sample, which to the best of our knowledge, have not been described for this reference material yet. When evaluating natural komatiites from the Gorgona Island, we find that spinel is common in a mineral assemblage (Kerr et al. 1996, Kamenetsky et al. 2010). However, we were surprised at having found spinel in GOR128-G, as this reference material should be homogeneous. Regarding minor elements, relative standard deviations are higher (up to $30 \%$ for $\mathrm{Na}, \mathrm{K}$, and $\mathrm{Mn}$; and up to $80 \%$ for $\mathrm{Cr}$ ) because operating conditions are close to the detection limit of the EPMA (0.01 wt.\%) in some cases. Nevertheless, the major and minor element analyses from EPMA-WDS reported herein are within error from the recommended values (Jochum et al. 2000, 2005), which is of fundamental importance for the use of internal standardization.

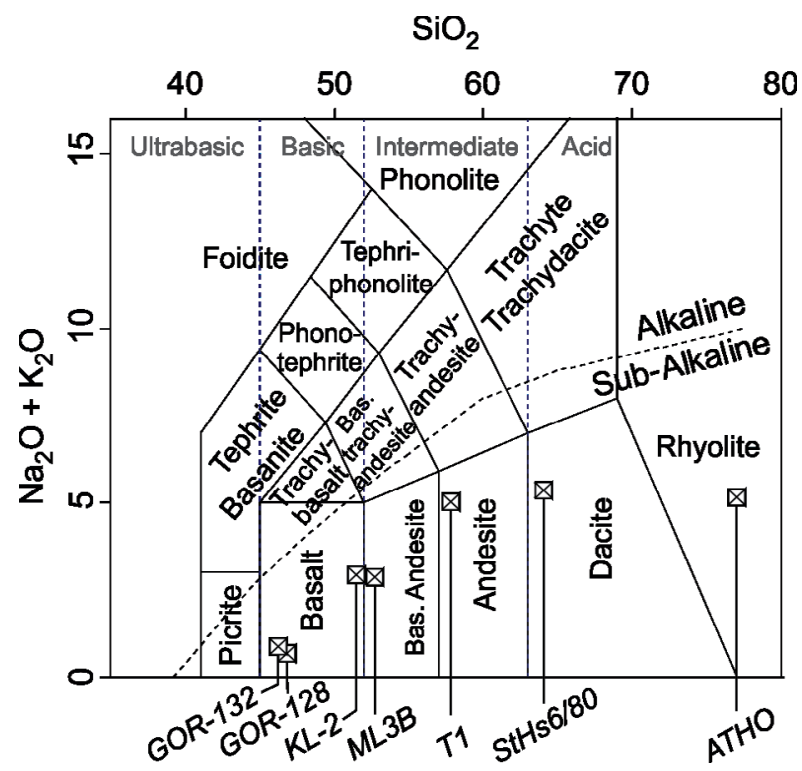

Figure 2. TAS (Total alkali vs. Silica) classification diagram following Bas et al. (1986) for the selected MPI-DING Glasses (Jochum et al. 2000). 
Table 3. Major element composition of the MPI-DING silicate glasses obtained via WDS-EPMA $(n=10)$ and the recommended values.

\begin{tabular}{|c|c|c|c|c|c|c|c|c|c|c|c|c|}
\hline \multirow{2}{*}{$\begin{array}{l}\text { Sample } \\
\text { ID }\end{array}$} & \multicolumn{3}{|c|}{ KL-2G } & \multicolumn{3}{|c|}{ GOR-128G } & \multicolumn{3}{|c|}{ GOR-132G } & \multicolumn{3}{|c|}{ StHs6/80G } \\
\hline & $\begin{array}{c}\text { Rec } \\
\text { Value }\end{array}$ & $\begin{array}{c}\text { Our } \\
\text { Value }\end{array}$ & \pm & $\begin{array}{c}\text { Rec } \\
\text { Value }\end{array}$ & $\begin{array}{c}\text { Our } \\
\text { Value }\end{array}$ & \pm & $\begin{array}{c}\text { Rec } \\
\text { Value }\end{array}$ & $\begin{array}{c}\text { Our } \\
\text { Value }\end{array}$ & \pm & $\begin{array}{c}\text { Rec } \\
\text { Value }\end{array}$ & $\begin{array}{c}\text { Our } \\
\text { Value }\end{array}$ & \pm \\
\hline $\mathrm{Na}_{2} \mathrm{O}$ & 2.35 & 2.38 & 0.04 & 0.574 & 0.62 & 0.21 & 0.83 & 0.82 & 0.03 & 4.44 & 3.99 & 0.07 \\
\hline $\mathrm{Al}_{2} \mathrm{O}_{3}$ & 13.3 & 13.4 & 0.06 & 9.91 & 10.3 & 3.14 & 11 & 10.9 & 0.05 & 17.8 & 18.0 & 0.08 \\
\hline $\mathrm{SiO}_{2}$ & 50.3 & 50.7 & 0.27 & 46.1 & 46.5 & 2.19 & 45.5 & 45.9 & 0.13 & 63.7 & 63.6 & 0.14 \\
\hline $\mathrm{MgO}$ & 7.34 & 7.42 & 0.06 & 26 & 25.9 & 8.73 & 22.4 & 22.6 & 0.11 & 1.97 & 2.02 & 0.05 \\
\hline $\mathrm{K}_{2} \mathrm{O}$ & 0.48 & 0.50 & 0.01 & 0.036 & 0.04 & 0.01 & 0.0308 & 0.04 & 0.01 & 1.29 & 1.34 & 0.02 \\
\hline $\mathrm{CaO}$ & 10.9 & 10.7 & 0.09 & 6.24 & 5.88 & 2.13 & 8.45 & 8.23 & 0.07 & 5.28 & 5.15 & 0.06 \\
\hline $\mathrm{TiO}_{2}$ & 2.56 & 2.60 & 0.03 & 0.288 & 0.29 & 0.09 & 0.306 & 0.31 & 0.01 & 0.703 & 0.71 & 0.01 \\
\hline $\mathrm{MnO}$ & 0.165 & 0.18 & 0.02 & 0.176 & 0.16 & 0.03 & 0.154 & 0.15 & 0.03 & 0.076 & 0.08 & 0.02 \\
\hline $\mathrm{FeO}$ & 10.7 & 10.7 & 0.10 & 9.81 & 9.61 & 1.56 & 10.1 & 10.3 & 0.09 & 4.37 & 4.42 & 0.07 \\
\hline $\mathrm{Cr}_{2} \mathrm{O}_{3}$ & $n i$ & 0.06 & 0.04 & $n i$ & 0.32 & 0.08 & $n i$ & 0.35 & 0.07 & $n i$ & 0.04 & 0.03 \\
\hline Total & & 98.5 & & & 99.7 & & & 99.7 & & & 99.4 & \\
\hline \multirow{2}{*}{$\begin{array}{l}\text { Sample } \\
\text { ID } \\
\end{array}$} & \multicolumn{4}{|c|}{ T1-G } & \multicolumn{4}{|c|}{ ML3B-G } & \multicolumn{4}{|c|}{ ATHO-G } \\
\hline & \multicolumn{3}{|c|}{ Our Value } & \pm & Rec Value & \multicolumn{2}{|c|}{ Our Value } & \pm & Rec Value & \multicolumn{2}{|c|}{ Our Value } & \pm \\
\hline $\mathrm{Na}_{2} \mathrm{O}$ & 3.13 & \multicolumn{2}{|c|}{3.06} & 0.06 & 2.4 & \multicolumn{2}{|c|}{2.40} & 0.05 & 3.75 & \multicolumn{2}{|c|}{2.35} & 0.09 \\
\hline $\mathrm{Al}_{2} \mathrm{O}_{3}$ & 17.1 & \multicolumn{2}{|c|}{17.8} & 0.15 & 13.6 & \multicolumn{2}{|c|}{13.7} & 0.05 & 12.2 & \multicolumn{2}{|c|}{12.3} & 0.12 \\
\hline $\mathrm{SiO}_{2}$ & 58.6 & \multicolumn{2}{|c|}{57.0} & 0.19 & 51.4 & \multicolumn{2}{|c|}{51.5} & 0.38 & 75.6 & \multicolumn{2}{|c|}{76.0} & 0.22 \\
\hline $\mathrm{MgO}$ & 3.75 & \multicolumn{2}{|c|}{3.96} & 0.05 & 6.59 & \multicolumn{2}{|c|}{6.57} & 0.09 & 0.103 & \multicolumn{2}{|c|}{0.10} & 0.01 \\
\hline $\mathrm{K}_{2} \mathrm{O}$ & 1.96 & \multicolumn{2}{|c|}{1.91} & 0.03 & 0.385 & \multicolumn{2}{|c|}{0.39} & 0.01 & 2.64 & \multicolumn{2}{|c|}{2.75} & 0.02 \\
\hline $\mathrm{CaO}$ & 7.1 & \multicolumn{2}{|c|}{7.23} & 0.09 & 10.5 & \multicolumn{2}{|c|}{10.1} & 0.08 & 1.7 & \multicolumn{2}{|c|}{1.64} & 0.05 \\
\hline $\mathrm{TiO}_{2}$ & 0.755 & & & 0.02 & 2.13 & & 10 & 0.02 & 0.255 & & 25 & 0.01 \\
\hline $\mathrm{MnO}$ & 0.127 & & & 0.02 & 0.17 & & 18 & 0.02 & 0.106 & & 09 & 0.01 \\
\hline $\mathrm{FeO}$ & 6.44 & & & 0.08 & 10.9 & & .7 & 0.11 & 3.27 & & 29 & 0.07 \\
\hline $\mathrm{Cr}_{2} \mathrm{O}_{3}$ & $n i$ & & & - & $n i$ & & 05 & 0.04 & $n i$ & & $\mathrm{dl}$ & - \\
\hline Total & & & & & & & .7 & & & & 3.8 & \\
\hline
\end{tabular}

Rec Value: recommended value; Bdl: below the detection limit (i.e., $0.01 \mathrm{wt} \%$ ); Ni: value not informed.

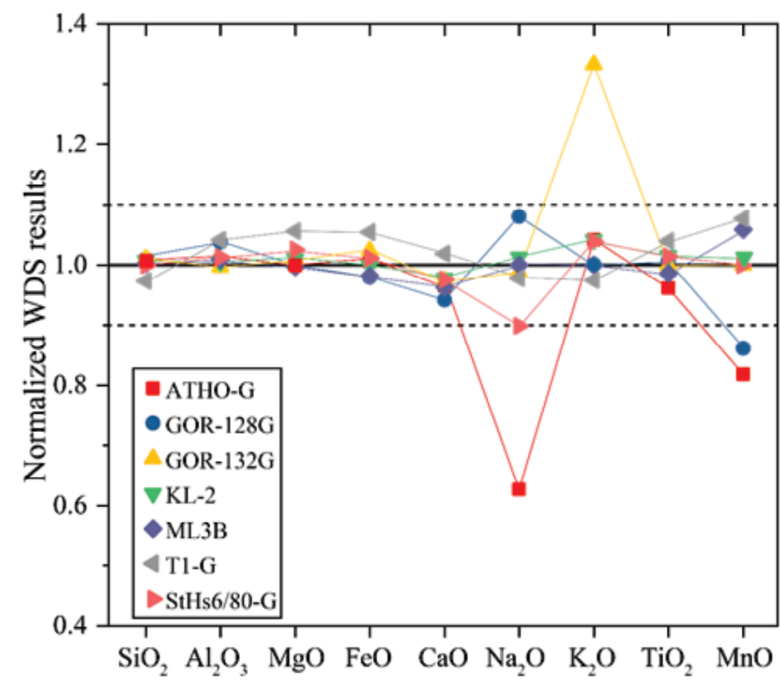

Figure 3. Mean EPMA-WDS concentration of the analyzed MPI-DING glasses normalized to the preferred values reported in the GEOREM (Jochum et al. 2007). Black dashed lines are two standard deviations. The colored markers represent the concentration of major elements in the following reference materials: Red squares represent ATHO-G, blue circles represent GOR128-G, yellow triangles represent GOR132-G, green triangles represent KL2-G, purple diamonds represent ML3B-G, grey triangles represent $\mathrm{T} 1-\mathrm{G}$, and orange triangles represent StHs6/80-G reference materials.

\section{Trace element composition of the silicate glasses}

Average trace element composition obtained via LA-ICP-MS and reduced with the in-house spreadsheets and reduction software, and the different ISs are listed in Table 4. To check for method accuracy and precision, the dataset obtained in this work was compared with the preferred values of Jochum et al. $(2007,2011)$ and the GEOREM (Jochum et al. 2005). The data from their study on these reference materials have been extensively double checked by several other analytical methods, such as SIMS (Secondary Ion Mass Spectrometry), ID-TIMS (Isotope Dilution Thermal Ionization Mass Spectrometry), and conventional acid digestion and solution nebulization ICP-MS. The results are presented below, separately for each reduction method.

\section{Trace elements results using in-house spreadsheets}

When our data reduced with in-house spreadsheets are compared with minimum and maximum literature values for the Kilauea Basalt (KL2-G), all elements are within error from the reported values (Jochum et al. 2005), which means that their concentration was correctly determined by the method (Fig. 5A). The same is observed for the komatiite GOR132-G 

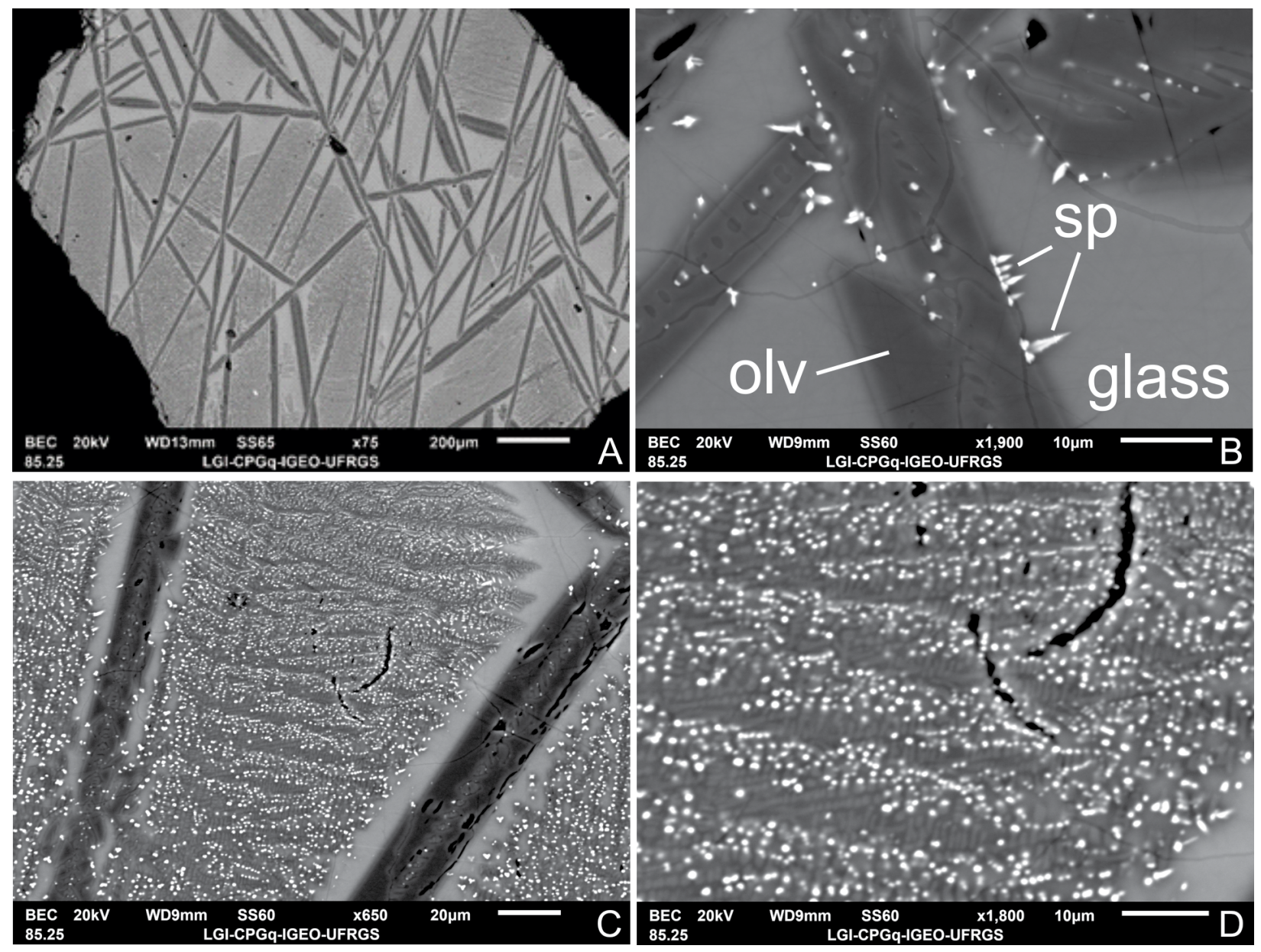

Figure 4. Back-scattered electron image of geological reference glass GOR128-G showing spinifex texture with elongated "platelike" olivine crystals in a glassy matrix (3A), as well as Fe-Mg zonation within the olivine crystals, and the presence of $\mathrm{Fe}-\mathrm{Cr} \mathrm{Spinel}$ micrometric crystals (3B), which are found disseminated in the glassy matrix in some portions $(3 \mathrm{C})$, intergrown with micrometric olivine quenched crystals (3D).

(Fig. 6A) and the rhyolite ATHO-G (Fig. 7A) reference materials. For the quartz diorite (T1-G), all elements are within error from literature values, except for $\mathrm{Ta}$, whose obtained value was below the minimum reported in the literature (Fig. 8A). For the GOR128-G komatiite (Fig. 9A), only $\mathrm{Nb}$ and Th did not produce values according to literature. For the StHs6/80-G andesite (Fig. 10A), trace elements are within error from literature values, except for $\mathrm{V}$, whose obtained concentration was below the minimum reported. The Mauna Loa Basaltic Glass (ML3B-G) has shown values within error from the reported GeoReM values, except for $\mathrm{Cr}, \mathrm{Sr}, \mathrm{Ce}$, and $\mathrm{Eu}$, which are ca. 10 to $0.04 \mu \mathrm{g} / \mathrm{g}$ lower than literature values (Fig. 11A).

If we consider mean values plus two standard deviations ( $95 \%$ confidence), the reproducibility of literature values increases. Almost all the values obtained with the reduction using in-house spreadsheets in our study are within the error reported in the literature, except for three cases only: Th, in the GOR128-G; V, in the StHs6/80-G; and Cr, in the ML3B-G. These trace elements show concentration values lower than the lowest values reported in the literature, although being at the same order of magnitude.

\section{Trace elements results using Glitter ${ }^{\circledR}$ software}

All the results obtained using Glitter ${ }^{\circledR}$ reduction software were also compared with the preferred values of Jochum et al.
(2005) (see Tab. 4) and are presented according to the isotope used as IS.

\section{Using ${ }^{29}$ Si as IS}

The KL2-G basalt presented 25 of the trace elements correctly determined and two within values that are lower than the preferred ones (Fig. 5B), which are $\mathrm{Cu}$ and Zn. The GOR132-G komatiite produced 24 trace elements correctly determined, except for $\mathrm{Cr}, \mathrm{Cu}$, and $\mathrm{Gd}$. Chromium and Gd presented values above the maximum values found in the literature, while $\mathrm{Cu}$ values were below the minimum reported (Fig. 6B).

For the ATHO-G, all trace elements were correctly determined, except for $\mathrm{Cu}$ (Fig. 7B), which presented values below the minimum reported. Out of all trace elements determined in the T1-G quartz diorite (Fig. 8B), 10 values vary slightly from the literature data and remain within the uncertainty of the method $(2 \sigma)$ : V, Sr, Y, La, Ce, Pr, Nd, Ho, Er, and Th. Again, $\mathrm{Cu}$ and $\mathrm{Zn}$ are in total disagreement with the literature values, with values below the minimum reported.

The GOR128-G presented two trace elements with values below the detection limit: $\mathrm{Rb}$ and $\mathrm{Ba}$ (Fig. 9B). For the same reference material, four trace elements presented values that differ from the literature: $\mathrm{Cu}$ had values below the minimum reported in the literature, and $\mathrm{Sm}, \mathrm{Ta}$, and Th had 


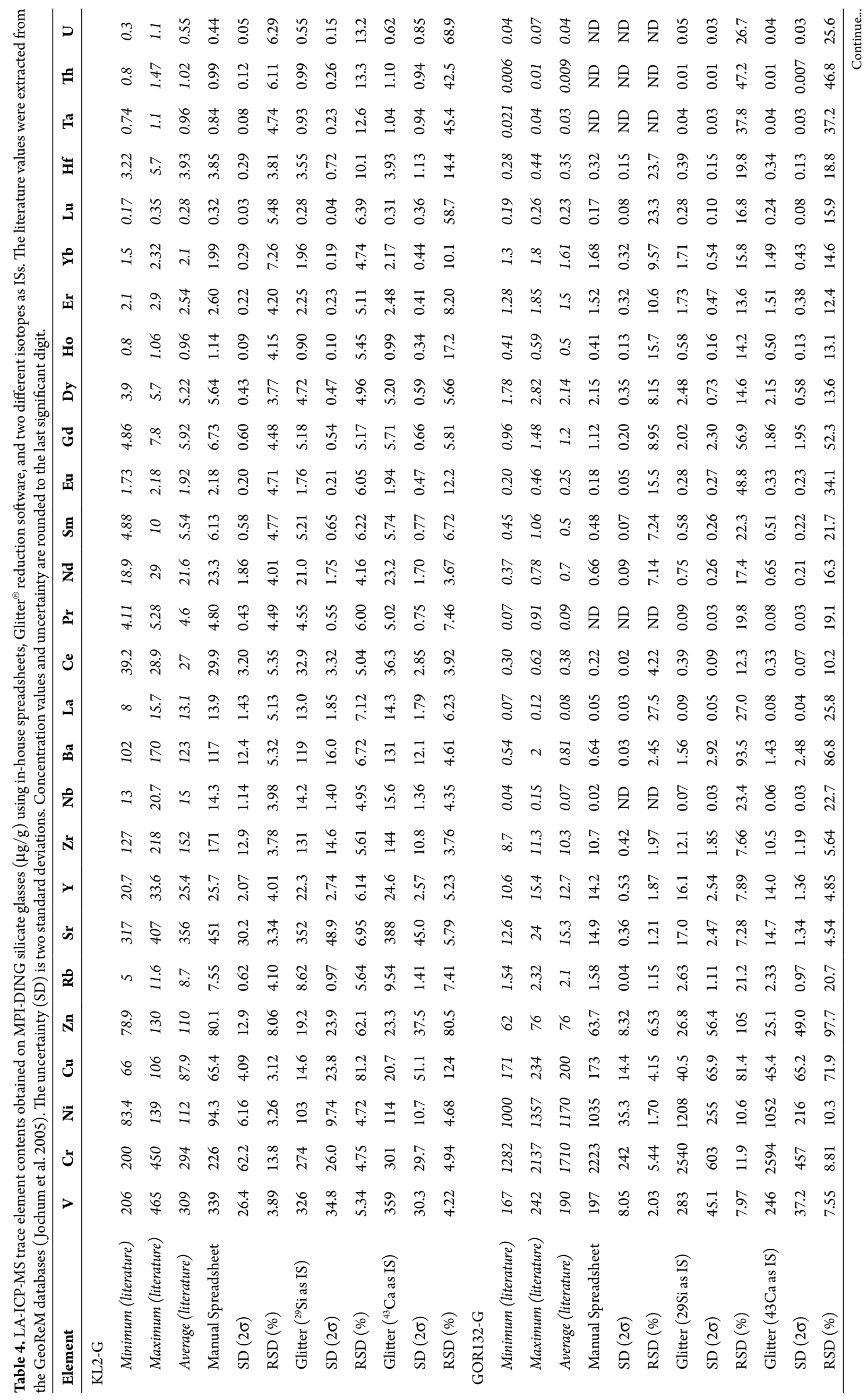




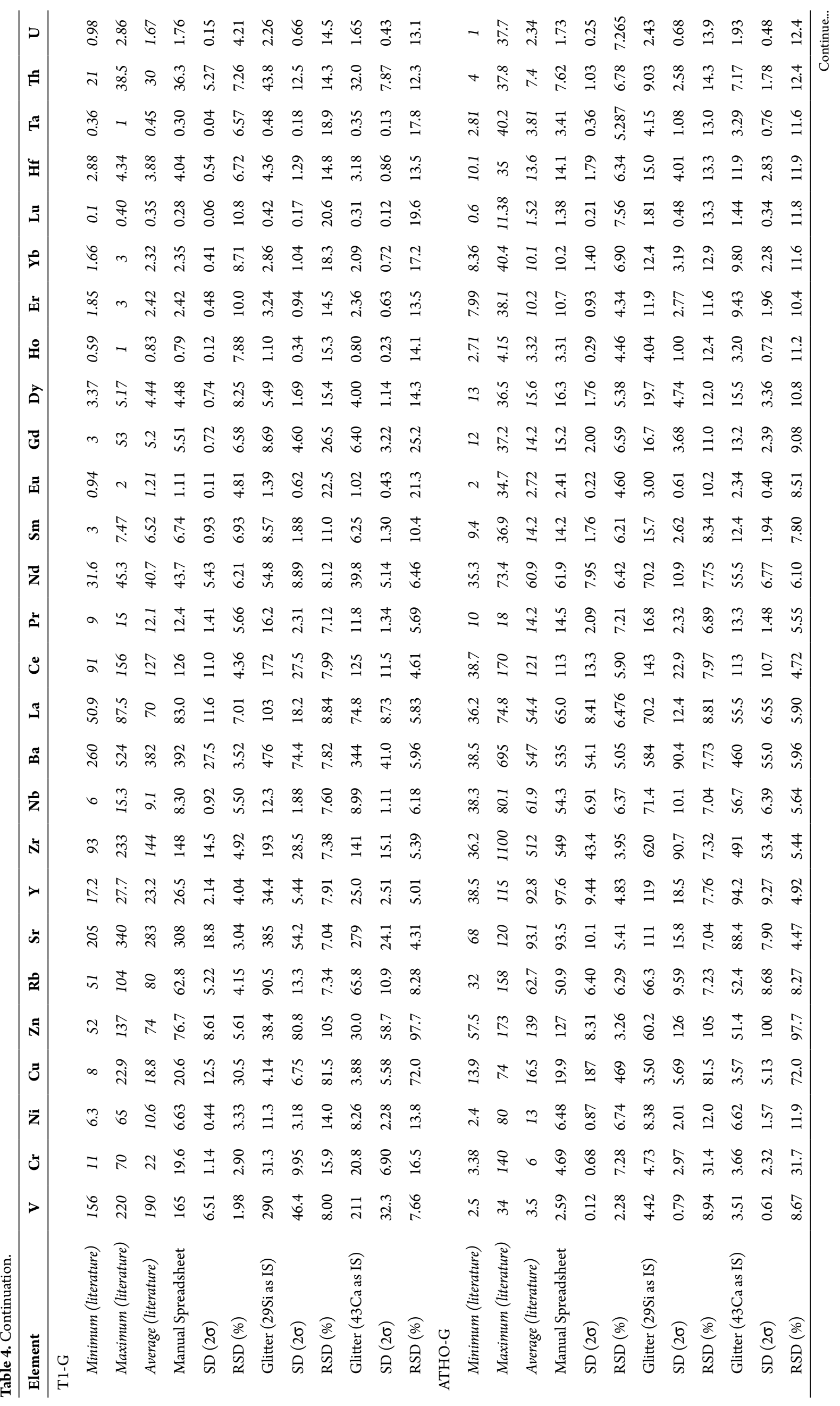




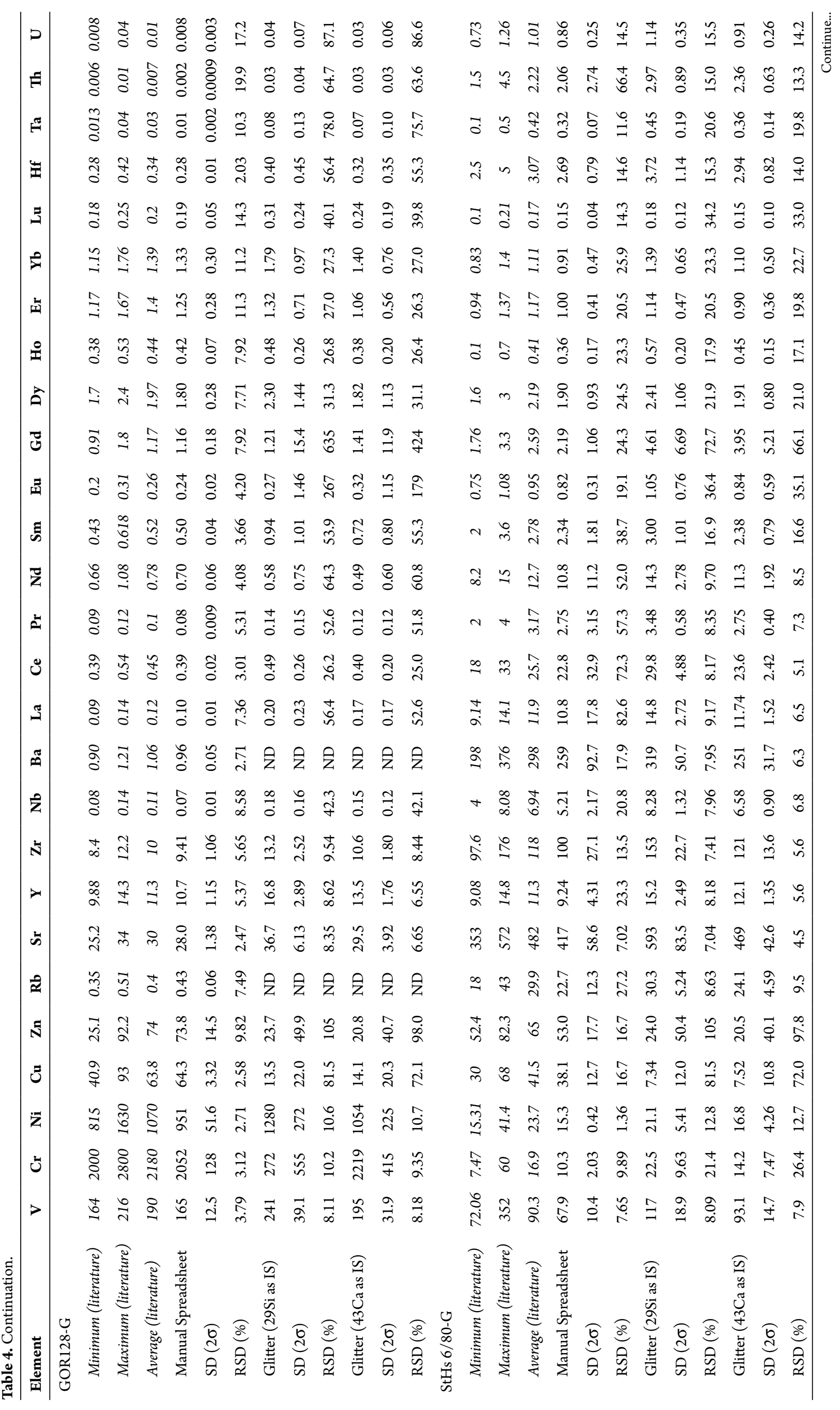


Table 4. Continuation.

\begin{tabular}{|c|c|c|c|c|c|c|c|c|c|c|c|c|c|c|c|}
\hline Element & $\mathbf{V}$ & $\mathbf{C r}$ & $\mathbf{N i}$ & $\mathbf{C u}$ & Zn & $\mathbf{R b}$ & Sr & $\mathbf{Y}$ & $\mathbf{Z r}$ & $\mathbf{N b}$ & Ba & $\mathbf{L a}$ & $\mathrm{Ce}$ & Pr & Nd \\
\hline \multicolumn{16}{|l|}{ ML3B-G } \\
\hline Minimum (literature) & 188 & 140 & 70 & 93.2 & 61 & 4.6 & 276 & 19.3 & 95.1 & 5 & 69.9 & 7.86 & 20.8 & 2.87 & 13.7 \\
\hline Maximum (literature) & 374 & 600 & 170 & 145 & 135 & 10 & 407 & 27.6 & 175 & 10.3 & 120 & 10.9 & 28.23 & 3.81 & 18.7 \\
\hline Average (literature) & 240 & 170 & 105 & 115 & 108 & 5.8 & 312 & 23.9 & 122 & 8.61 & 80 & 8.96 & 23.1 & 3.43 & 16.7 \\
\hline Manual Spreadsheet & 249 & 129 & 85.7 & 92.5 & 83.7 & 4.46 & 257 & 18.9 & 97.4 & 6.28 & 65.6 & 7.61 & 18.6 & 2.75 & 13.3 \\
\hline $\mathrm{SD}(2 \sigma)$ & 10.9 & 2.64 & 4.40 & 5.11 & 6.97 & 0.45 & 21.3 & 1.67 & 9.11 & 0.92 & 5.93 & 0.97 & 2.17 & 0.39 & 1.17 \\
\hline RSD (\%) & 2.19 & 1.02 & 2.57 & 2.76 & 4.16 & 5.01 & 4.13 & 4.42 & 4.68 & 7.32 & 4.52 & 6.36 & 5.84 & 7.14 & 4.39 \\
\hline Glitter (29Si as IS) & 372 & 178 & 105 & 21.8 & 41.9 & 5.69 & 352 & 29.1 & 145.7 & 9.88 & 77.8 & 10.3 & 24.5 & 3.44 & 17.2 \\
\hline $\operatorname{SD}(2 \sigma)$ & 59.2 & 41.5 & 22.5 & 35.6 & 88.0 & 1.56 & 49.6 & 4.55 & 21.4 & 1.45 & 12.9 & 1.86 & 3.94 & 0.51 & 2.86 \\
\hline RSD (\%) & 8.0 & 11.6 & 10.7 & 81.4 & 105 & 13.7 & 7.0 & 7.8 & 7.4 & 7.3 & 8.3 & 9.0 & 8.1 & 7.5 & 8.3 \\
\hline Glitter (43Ca as IS) & 312 & 168 & 88.7 & 23.6 & 37.8 & 4.73 & 295 & 24.4 & 122 & 8.30 & 65.0 & 8.65 & 20.5 & 2.88 & 14.4 \\
\hline $\mathrm{SD}(2 \sigma)$ & 47.1 & 30.6 & 18.4 & 33.9 & 73.8 & 1.35 & 24.5 & 2.32 & 12.79 & 0.96 & 8.38 & 1.03 & 1.88 & 0.34 & 1.91 \\
\hline RSD (\%) & 7.5 & 9.1 & 10.4 & 71.9 & 97.7 & 14.3 & 4.1 & 4.8 & 5.2 & 5.8 & 6.4 & 6.0 & 4.6 & 6.0 & 6.6 \\
\hline Element & Sm & Eu & & Gd & Dy & Ho & Er & & $\mathbf{Y b}$ & $\mathbf{L u}$ & Hf & Ta & & Th & $\mathbf{U}$ \\
\hline \multicolumn{16}{|l|}{ ML3B-G } \\
\hline Minimum (literature) & 3.92 & 1.48 & & 3.83 & 3.63 & 0.69 & 1.73 & & 1.41 & 0.19 & 2.07 & 0.4 & & 0.45 & 0.35 \\
\hline Maximum (literature) & 5.31 & 1.83 & & 8 & 5.6 & 1.04 & 2.74 & & 2.62 & 0.36 & 4.6 & 0.64 & & 0.82 & 0.66 \\
\hline Average (literature) & 4.75 & 1.67 & & 5.23 & 4.81 & 0.91 & 2.44 & & 2.05 & 0.29 & 3.22 & 0.55 & & 0.54 & 0.44 \\
\hline Manual Spreadsheet & 3.73 & 1.30 & & 4.24 & 4.02 & 0.77 & 2.06 & & 1.68 & 0.22 & 2.64 & 0.42 & & 0.46 & 0.33 \\
\hline $\operatorname{SD}(2 \sigma)$ & 0.47 & 0.20 & & 0.43 & 0.34 & 0.07 & 0.09 & & 0.11 & 0.02 & 0.28 & 0.04 & & 0.04 & 0.03 \\
\hline RSD (\%) & 6.32 & 7.65 & & 5.04 & 4.18 & 4.39 & 2.33 & & 3.22 & 4.17 & 5.31 & 4.90 & & 3.94 & 5.31 \\
\hline Glitter (29Si as IS) & 5.11 & 1.72 & & 7.13 & 5.42 & 1.05 & 2.55 & & 2.23 & 0.27 & 3.40 & 0.57 & & 0.65 & 0.46 \\
\hline $\mathrm{SD}(2 \sigma)$ & 1.04 & 0.48 & & 3.19 & 1.45 & 0.28 & 0.67 & & 0.69 & 0.11 & 0.96 & 0.17 & & 0.20 & 0.14 \\
\hline RSD (\%) & 10.2 & 14.1 & & 22.4 & 13.4 & 13.5 & 13.2 & & 15.6 & 20.1 & 14.2 & 15.1 & & 15.7 & 15.4 \\
\hline Glitter (43Ca as IS) & 4.28 & 1.47 & & 5.95 & 4.55 & 0.88 & 2.14 & & 1.87 & 0.24 & 2.85 & 0.48 & & 0.55 & 0.39 \\
\hline $\operatorname{SD}(2 \sigma)$ & 0.82 & 0.37 & & 2.53 & 1.1 & 0.22 & 0.52 & & 0.54 & 0.09 & 0.73 & 0.13 & & 0.15 & 0.11 \\
\hline RSD (\%) & 9.6 & 12.6 & & 21.2 & 12.1 & 12.4 & 12.1 & & 14.4 & 17.7 & 12.7 & 13.8 & & 13.7 & 14.0 \\
\hline
\end{tabular}

ND: not detected. It means the counts obtained for the element are below the detection limit of the technique; RSD \%: relative standard deviation \%.

concentrations that were above the maximum values reported. For the StHs6/80-G andesite, all elements were correctly determined, except for $\mathrm{Cu}$ and $\mathrm{Zn}$, whose values were below the minimum values, and $\mathrm{Gd}$ that had a concentration value above the maximum reported (Fig. 10B). For the ML3B-G, all trace elements were correctly determined, except again for $\mathrm{Cu}$ and $\mathrm{Zn}$, whose values were below the minimum reported in the literature (Fig. 11B).

\section{Using ${ }^{43} \mathrm{Ca}$ as IS}

The results obtained for the KL2-G basalt (Fig. 5C) presented only two values below the minimum reported, which are $\mathrm{Cu}$ and $\mathrm{Zn}$. For the GOR132-G komatiite, the same pattern obtained for ${ }^{29} \mathrm{Si}$ as IS was observed for ${ }^{43} \mathrm{Ca}$. Chromium and $\mathrm{Gd}$ presented values above the maximum reported, while $\mathrm{Cu}$ and $\mathrm{Zn}$ presented values below the minimum found in the literature (Fig. 6C).

In the ATHO-G, the only trace element that presented a value below the minimum was $\mathrm{Cu}$ (Fig. $7 \mathrm{C}$ ). In the quartz diorite T1-G, only $\mathrm{Cu}, \mathrm{Zn}$, and Th had values below the minimum reported in the literature (Fig. 8C). The GOR128-G presented the same two trace elements with values below the detection limit: $\mathrm{Rb}$ and $\mathrm{Ba}$ (Fig. 9C). The trace elements $\mathrm{Cu}, \mathrm{Zn}, \mathrm{Nd}$, and Er presented concentrations below the minimum reported, while $\mathrm{La}, \mathrm{Sm}$, Ta, and Th had values above the maximum found in the literature. For the StHs6/80-G andesite, the elements with erroneous values were $\mathrm{Cu}$ and $\mathrm{Zn}$, with values below the minimum reported in the literature, and Gd concentration above the maximum reported (Fig. 10C).

Finally, for the ML3B-G, the exceptions were $\mathrm{Cu}$ and $\mathrm{Zn}$, which presented values below the minimum found in the literature (Fig. 11C).

If we compare Glitter ${ }^{\circledR}$ data with the in-house spreadsheet reduced results, when we consider the mean values plus two standard deviations, a higher reproducibility of the literature data for MPI-DING glasses is observed, but some elements still differ from the literature values. By using ${ }^{29} \mathrm{Si}$ as IS, concentration data always have a higher standard deviation for several elements. In some cases, even higher than $50 \%$ (see Tab. 4). Although the use of ${ }^{43} \mathrm{Ca}$ as IS has produced more results in disagreement with the literature, the 


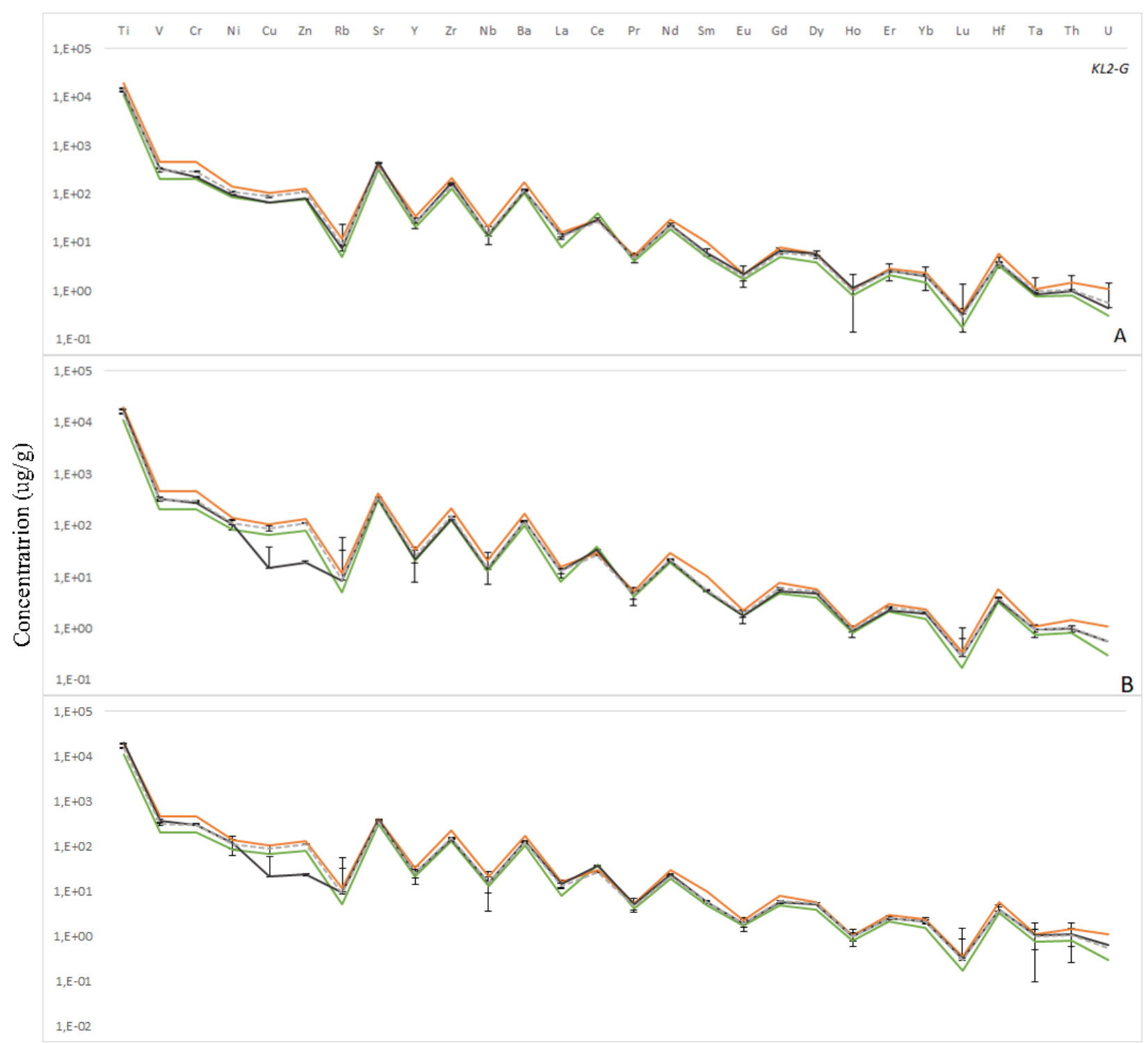

Figure 5. LA-ICP-MS trace element concentration of MPI-DING silicate glass KL2-G (Kilauea Basalt) obtained in this study (solid black lines), trace element concentration corrected with RSF (dashed grey lines) and compared with the minimum and maximum values reported in the literature (green and orange solid lines, respectively). Error bars are two standard deviations $(2 \sigma)$ of the mean value. (A) Trace elements of KL2-G using ${ }^{43} \mathrm{Ca}$ as IS and in-house spreadsheets-reduced data. (B) Trace elements of KL2-G using ${ }^{29} \mathrm{Si}$ as IS and software-reduced data. (C) Trace elements of KL2-G using ${ }^{43} \mathrm{Ca}$ as IS and software reduction. Literature data were extracted from Jochum et al. (2005).

standard deviation obtained for such results is smaller than that obtained for ${ }^{29} \mathrm{Si}$ as IS. The data obtained using in-house spreadsheets presented the largest number of results in agreement with the data found in the literature for the same trace elements. Some of the values found in both reduction methods are quite different from the maximum or minimum values in the literature, and the reason for such inconsistencies are discussed below.

\section{RSF values}

The RSF values, calculated using Equation 3, are shown in Figures 12 and 13. The trace element contents that were considered correct presented an RSF value that ranges from 5 to $10 \%$ of the unity (between \pm 1.05 and \pm 1.10 in the charts). The trace elements that represent a slight difference from the literature, but remain within the uncertainty of the method, had an RSF value around $15 \%$. Trace elements with a great RSF value represent the elements not detected or the elements in total disagreement with literature data.

\section{DISCUSSION}

After selecting appropriate isotopes to avoid isobaric interferences, we can examine each group of results separately to understand the causes for outliers. The results obtained with in-house spreadsheets for trace element contents of MPI-DING silicate glasses have been correctly determined when compared with literature values. A few exceptions were observed, which are, in all cases, lower than the minimum values reported in the literature, confirming the systematic negative shift for trace elements when NIST SRM 61x $(x=0,2$, 4 , etc.) series are used as a calibration standard (Jochum et al. 2007, Chen et al. 2011, Kimura and Chang 2012, Zhang et al. 2019). These results cannot be reconciled by isobaric interferences, for example, which would increase the concentration 


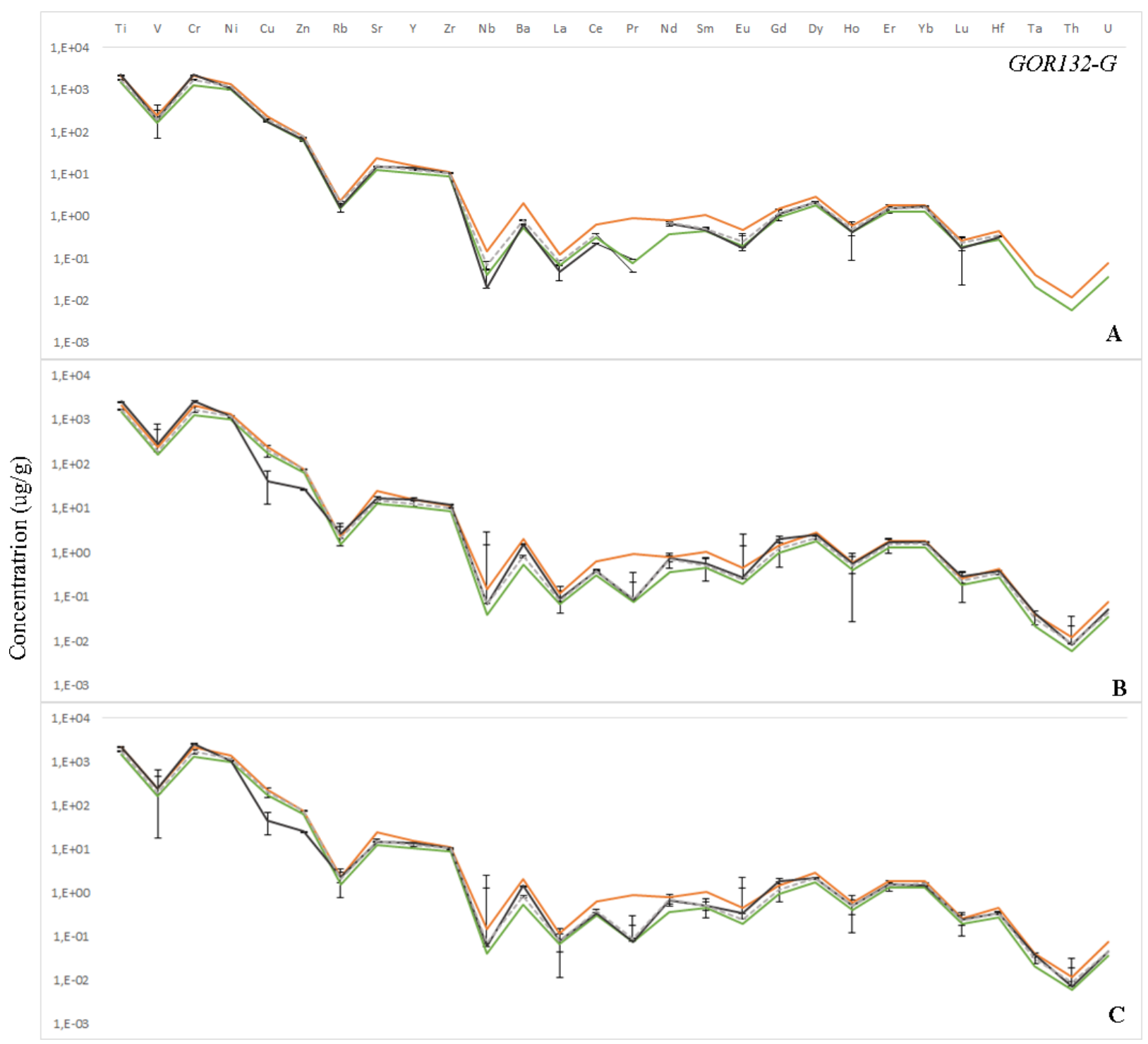

Figure 6. LA-ICP-MS trace element concentration of MPI-DING silicate glass GOR132-G (Gorgona Island Komatiite) obtained in this study (solid black lines), trace element concentration corrected with RSF (dashed grey lines) and compared with the minimum and maximum values reported in the literature (green and orange solid lines, respectively). Error bars are two standard deviations $(2 \sigma)$ of the mean value. (A) Trace elements of GOR132-G using ${ }^{43} \mathrm{Ca}$ as IS and in-house spreadsheets-reduced data. (B) Trace elements of GOR132-G using ${ }^{29} \mathrm{Si}$ as IS and software-reduced data. (C) Trace elements of GOR132-G using ${ }^{43} \mathrm{Ca}$ as IS and software reduction. Literature data were extracted from Jochum et al. (2005).

of the trace elements due to a higher count rate during the analyses. MPI-DING glasses are widely reported in the literature and, at least for major elements measured via EPMAWDS, are homogeneous in composition (Jochum et al. 2000, Jochum and Stoll 2008). However, it should be noted that the composition of the major elements in NIST SRM glasses are different from the composition of major elements in standards of geological origin (Jochum and Stoll 2008) and can lead to errors based on matrix effects and the reduction step. The Gorgona komatiite glasses, especially GOR-128G, have been described in the literature as having quenched olivine crystals (Jochum et al. 2000). This is also found in our samples, in addition to the presence of $\mathrm{Fe}-\mathrm{Cr}$ spinel, the former being a possible explanation for the lower values of Th found in our study, given that $D_{T h}^{\text {olv/melt }}$ is extremely low for mafic melts, at the order of $10^{-5}$ (Leitzke et al. 2016). Jochum and Stoll (2008) argue that trace element content for refractory lithophile elements is homogeneous in MPI-DING glasses.
However, some of the trace element reported values show an extensive range of concentrations, for example, $\mathrm{Cr}$ contents in the ML3B-G range from 140 to $600 \mu \mathrm{g} / \mathrm{g}$ (Fig. 3), which corroborates the value of $129 \pm 4$ measured in our study as being related to the natural heterogeneity of the sample. The same argument could be used for the measured value of $65 \pm 5$ obtained in our study for $\mathrm{V}$ in the StHs6/80-G, while reported literature values show a wide range, from 72 to $350 \mu \mathrm{g} / \mathrm{g}$. In fact, according to Jochum and Stoll (2008), heterogeneous distribution of trace elements in MPI-DING glasses has been observed for siderophile (e.g., platinum group elements and gold), as well as for some chalcophile elements $(\mathrm{Bi}, \mathrm{Sn}$, and $\mathrm{Cu})$. This is explained by element fractionation and loss of volatile components during the fusion and production of theses glasses, as well as platinum crucible, by the formation of alloys (Eggins and Shelley 2002). Even though both $\mathrm{V}$ and $\mathrm{Cr}$ are mainly lithophile, they tend to form oxide minerals in the spinel group in nature, for example, chromite 


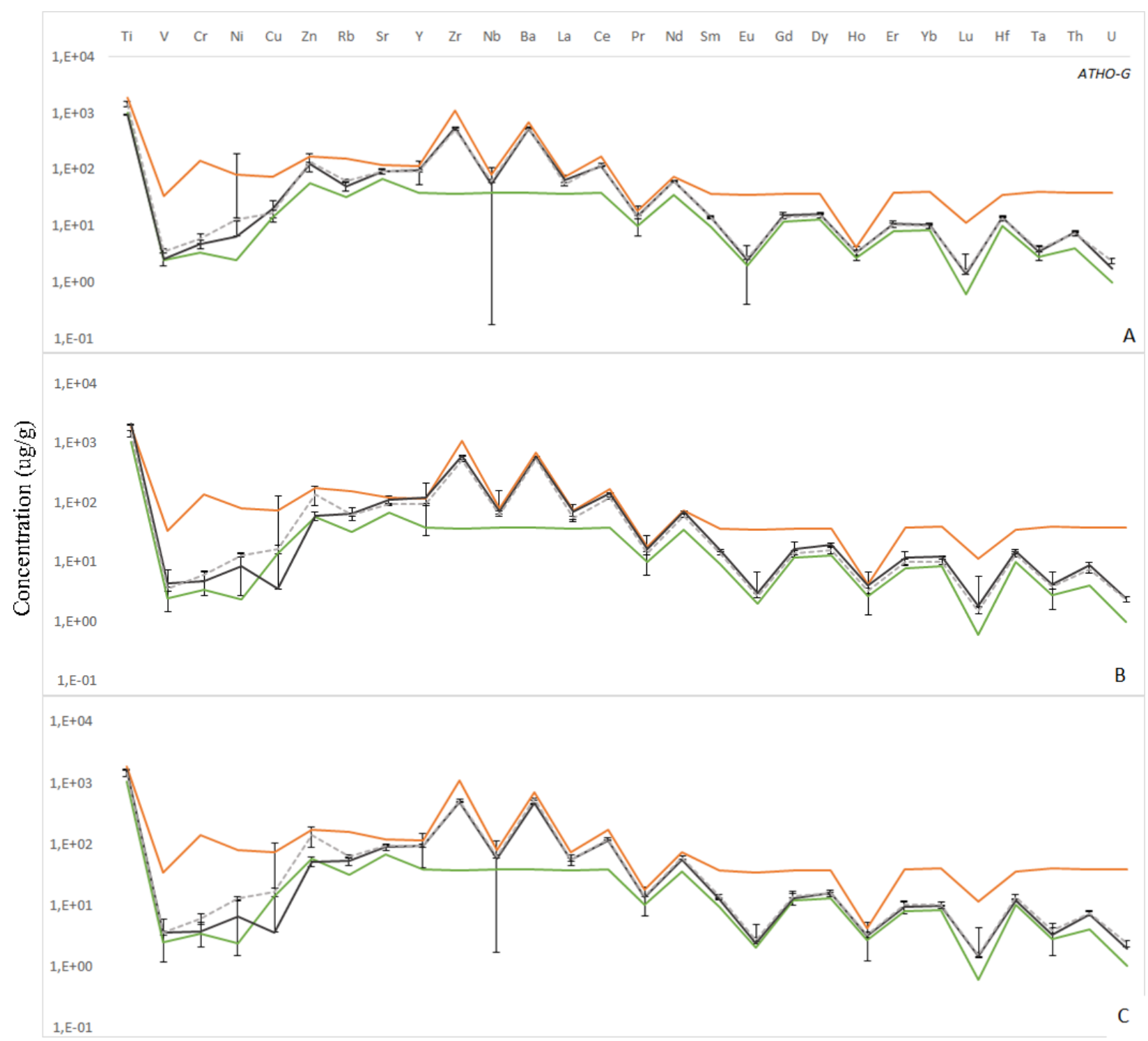

Figure 7. LA-ICP-MS trace element concentration of MPI-DING silicate glass ATHO-G (Rhyolite) obtained in this study (solid grey lines), trace element concentration corrected with RSF (dashed black lines) and compared with the minimum and maximum values reported in the literature (green and orange solid lines, respectively). Error bars are two standard deviations $(2 \sigma)$ of the mean value. (A) Trace elements of ATHO-G using ${ }^{43} \mathrm{Ca}$ as IS and in-house spreadsheets reduction data. (B) Trace elements of ATHO-G using ${ }^{29} \mathrm{Si}$ as IS and software-reduced data, (C) trace elements of ATHO-G using ${ }^{43} \mathrm{Ca}$ as IS and software reduction. Literature data were extracted from Jochum et al. (2005).

$\left(\mathrm{FeCr}_{2} \mathrm{O}_{4}\right)$ and coulsonite $\left(\mathrm{FeV}_{2} \mathrm{O}_{4}\right)$, which are highly refractory. If even at the nano- or micro-scale, the formation of these oxide phases occurred. This could affect the homogeneity of the glasses and result in lower values.

The software-reduced data showed some results outside the expectations for the reference materials analyzed. It is important to highlight that the measurement of the trace elements in this round was the same for both ISs. The IS for calculation of the mean values was changed after the measurements, only affecting the reduction step. When analyzing the data obtained using ${ }^{29} \mathrm{Si}$ as IS, $\mathrm{Cu}$ is in disagreement in all glasses, with values lower than expected. This may be due to several factors, including fractionation effects in chalcophile/siderophile and volatile elements (Horn and von Blanckenburg 2007, Jochum et al. 2014), mass load of the sample, volatility effect caused by a non-stoichiometric sampling (Gaboardi and Humayun 2009), and even heterogeneities due alloy formations with the platinum crucible used to produce the glasses (Jochum et al. 2000, Eggins and Shelley 2002). These very same factors can explain the low value obtained for Zn in KL2-G, T1-G, StHs6/80-G, and ML3B-G glasses. As a chalcophile element with moderate volatility, the $\mathrm{Zn}$ values are affected by fractionation and the mass loaded into the ICP-MS (Jochum et al. 2012, 2014).

Rubidium and Ba presented signal values below the detection limit in GOR128-G. It does not necessarily mean that these elements are absent (they were detected before when the results were reduced using spreadsheets). One of the potential causes for this error is the background signal with a value higher than the signal measured for these elements, and this factor can be corrected in the future. These elements are also prone to high fractionation, associated to the medium boiling and melting points (in the case of $\mathrm{Rb}$ ), and oxide formation for Ba, both of which will contribute to lower peak 


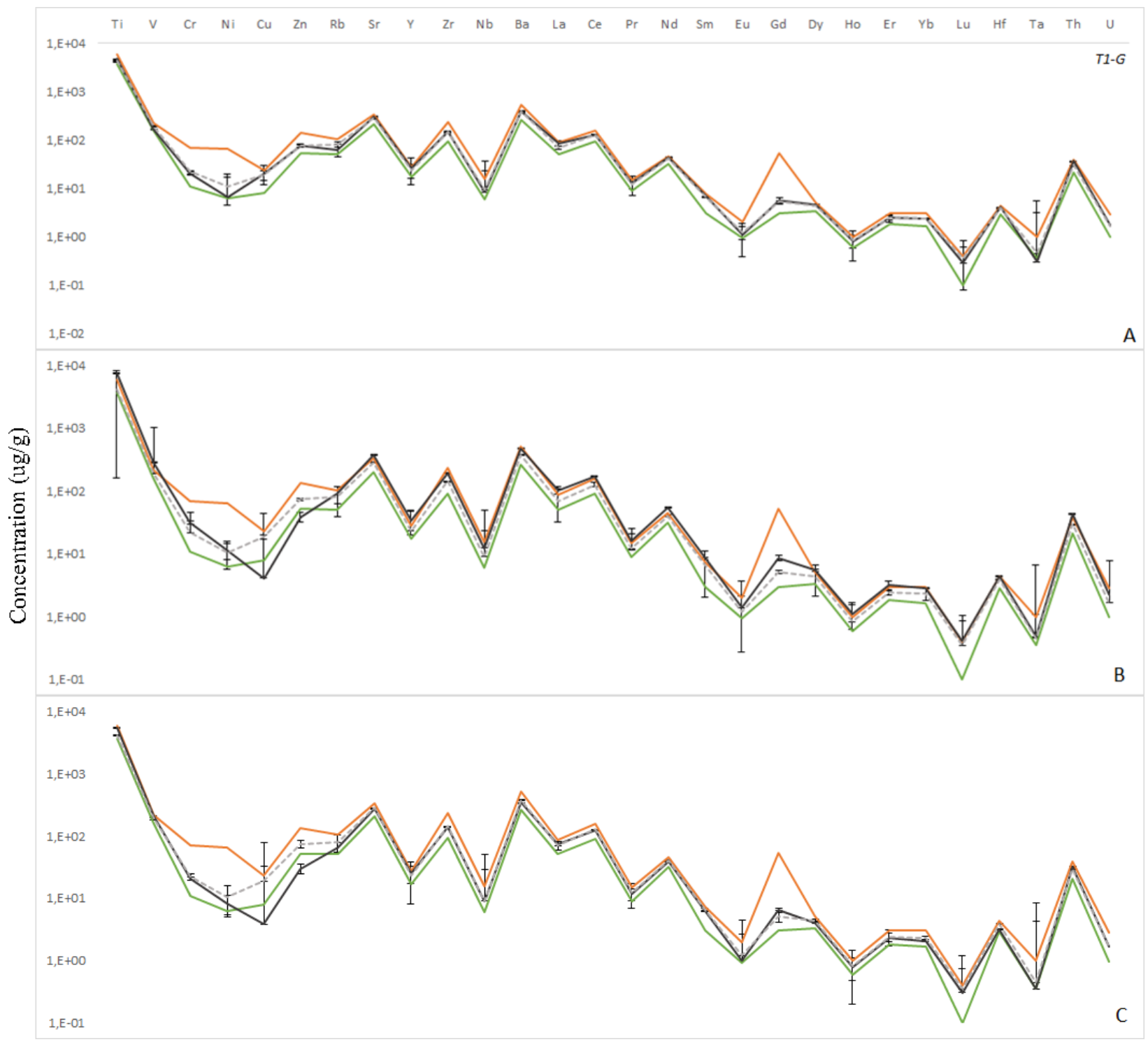

Figure 8. LA-ICP-MS trace element concentration of MPI-DING silicate glass T1-G (quartz diorite Alps) obtained in this study (solid grey lines), trace element concentration corrected with RSF (dashed black lines) and compared with the minimum and maximum values reported in the literature (green and orange solid lines, respectively). Error bars are two standard deviations $(2 \sigma)$ of the mean value. (A) Trace elements of T1-G using ${ }^{43} \mathrm{Ca}$ as IS and in-house spreadsheets-reduced data. (B) Trace elements of T1-G using ${ }^{29} \mathrm{Si}$ as IS and software-reduced data. (C) Trace elements of T1-G using ${ }^{43} \mathrm{Ca}$ as IS and software reduction. Literature data were extracted from Jochum et al. (2005).

intensities (Outridge et al. 1997, Gaboardi and Humayun 2009). The high mean values obtained for the lithophile element Ta in GOR128-G can also be explained by formation of isobaric molecules. We can mention, for example, ${ }^{141} \mathrm{Pr}^{40} \mathrm{Ar}$ and ${ }^{165} \mathrm{Ho}^{16} \mathrm{O}$ as molecules with the same mass as $\mathrm{Ta}$ (Gaboardi and Humayun 2009). The strong matrix effect in elements of group 3 and REE observed by Chan et al. (2000) must also be considered, related to the low second ionization potential of these elements. In GOR132-G, Cr presented a mean value higher than expected, but it is known that the formation of Cr-rich "islands" in basaltic glasses (like BCR-2G observed by Rocholl 1998) can increase the average concentration obtained. The formation of $\mathrm{Cr}_{2}{ }^{6+}$ dimers in spinel-like structures is also observed in the cooling phase of the melts that may influence the increased concentration of $\mathrm{Cr}$ (Colson et al. 2000, Jochum et al. 2000). The presence of olivine and $\mathrm{Fe}-\mathrm{Cr}$ spinel in this glass is an evident cause of heterogeneity and increased concentration of $\mathrm{Cr}$. Lithophile elements such as $\mathrm{Gd}$ (in GOR132 and StHs6/80-G), Sm, and Th (in GOR128-G) also presented increased values, and even a minimum formation of oxides like ${ }^{139} \mathrm{La}^{18} \mathrm{O},{ }^{131} \mathrm{Xe}^{16} \mathrm{O}$, and ThO whose intensities are added to $\mathrm{Gd}, \mathrm{Sm}$, and $\mathrm{Th}$, increasing the mean value (Gaboardi and Humayun 2009). Nevertheless, there is abundant literature related to the heterogeneity of the lithophile elements found in reference glasses such as NIST-SRM and MP-DING, which corroborate this hypothesis (Jochum et al. 2000, 2005, Eggins and Shelley 2002, Kempenaers et al. 2003, Regnery et al. 2010).

The data obtained using Glitter ${ }^{\circledR}$ software and ${ }^{43} \mathrm{Ca}$ as IS are slightly different from the literature compared to the data obtained using ${ }^{29} \mathrm{Si}$ as IS. Note the presence of $\mathrm{Cu}$ as an outlier in all reference glasses used in this work. Only two elements showed values different from the literature using ${ }^{43} \mathrm{Ca}$ and not ${ }^{29} \mathrm{Si}$, which are La in the GOR128-G sample, probably related to the formation of ${ }^{139} \mathrm{La}^{16} \mathrm{O}$ species, and $\mathrm{Zn}$ in the GOR132-G sample, probably caused by fractionation. These 


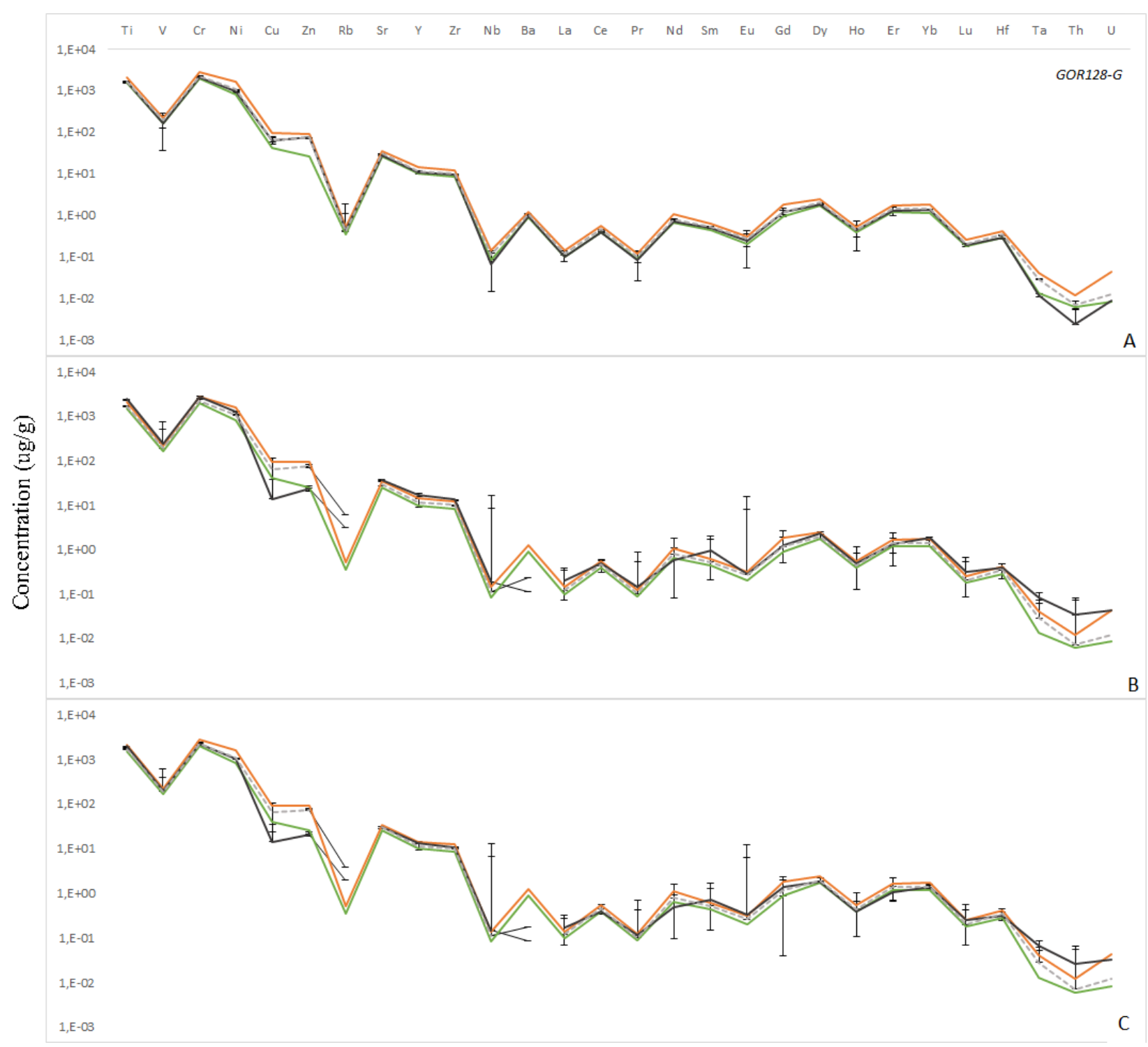

Figure 9. LA-ICP-MS trace element concentration of MPI-DING silicate glass GOR128-G (Gorgona Island Komatiite) obtained in this study (solid black lines), trace element concentration corrected with RSF (dashed grey lines) and compared with the minimum and maximum values reported in the literature (green and orange solid lines, respectively). Error bars are two standard deviations $(2 \sigma)$ of the mean value. (A) Trace elements of GOR128-G using ${ }^{43} \mathrm{Ca}$ as IS and in-house spreadsheets reduction data. (B) Trace elements of GOR128-G using ${ }^{29} \mathrm{Si}$ as IS and software-reduced data. (C) Trace elements of GOR128-G using ${ }^{43} \mathrm{Ca}$ as IS and software reduction. Literature data were extracted from Jochum et al. (2005).

results corroborate the data of Jenner and Arevalo Jr. (2016), and Jenner and O'Neill (2012) that showed that the use of ${ }^{29} \mathrm{Si}$ as IS with NIST SRM glasses as external standard leads to an increase in element fractionation with decreasing volatility, and that siderophile and lithophile elements are prone to negative fractionation when compared to ${ }^{43} \mathrm{Ca}$, for example, being necessary to apply a matrix correction to increase accuracy. However, when ${ }^{43} \mathrm{Ca}$ is used as IS, as in our study, even for non-matrix matching external standards, laser induced element fractionation is less significant and has fewer deviation from the literature values (Jenner and Arevalo Jr. 2016).

The variation obtained in the values for the trace elements of our LA-ICP-MS analysis may also have been caused by other fractionation sources, like laser-induced element fractionation, which is caused by decreasing the laser pit size during progressive ablation (e. g. Eggins et al. 1998, Jenner and Arevalo Jr. 2016). Whenever this occurs, the count rates for different elements and their ratio can vary progressively with time during the analyses, being not representative of the sample itself (e.g., Fryer et al. 1995, Eggins et al. 1998, Rege et al. 2008, Jenner and O'Neill 2012). It should be noted that these analyses were all performed in low resolution, which does not resolve peaks in nearby masses and may cause interferences, decreasing sensitivity. Another aspect that could increase uncertainty in our analyses is the fact that the sample holder is individual, so that the NIST-610/612 glasses had to be measured before and after the MPI-DING glasses by voiding the chamber and emptying it once again, which is not ideal, given that laser ablation parameters can vary during this procedure (Rege et al. 2008, Russo et al. 2013, Arevalo Jr. 2014, Jenner and Arevalo Jr. 2016). All these factors show how important it is to document trace element analyses in reference materials when implementing a methodology for their analyses in each geochemical laboratory, not only for comparing data accuracy and 


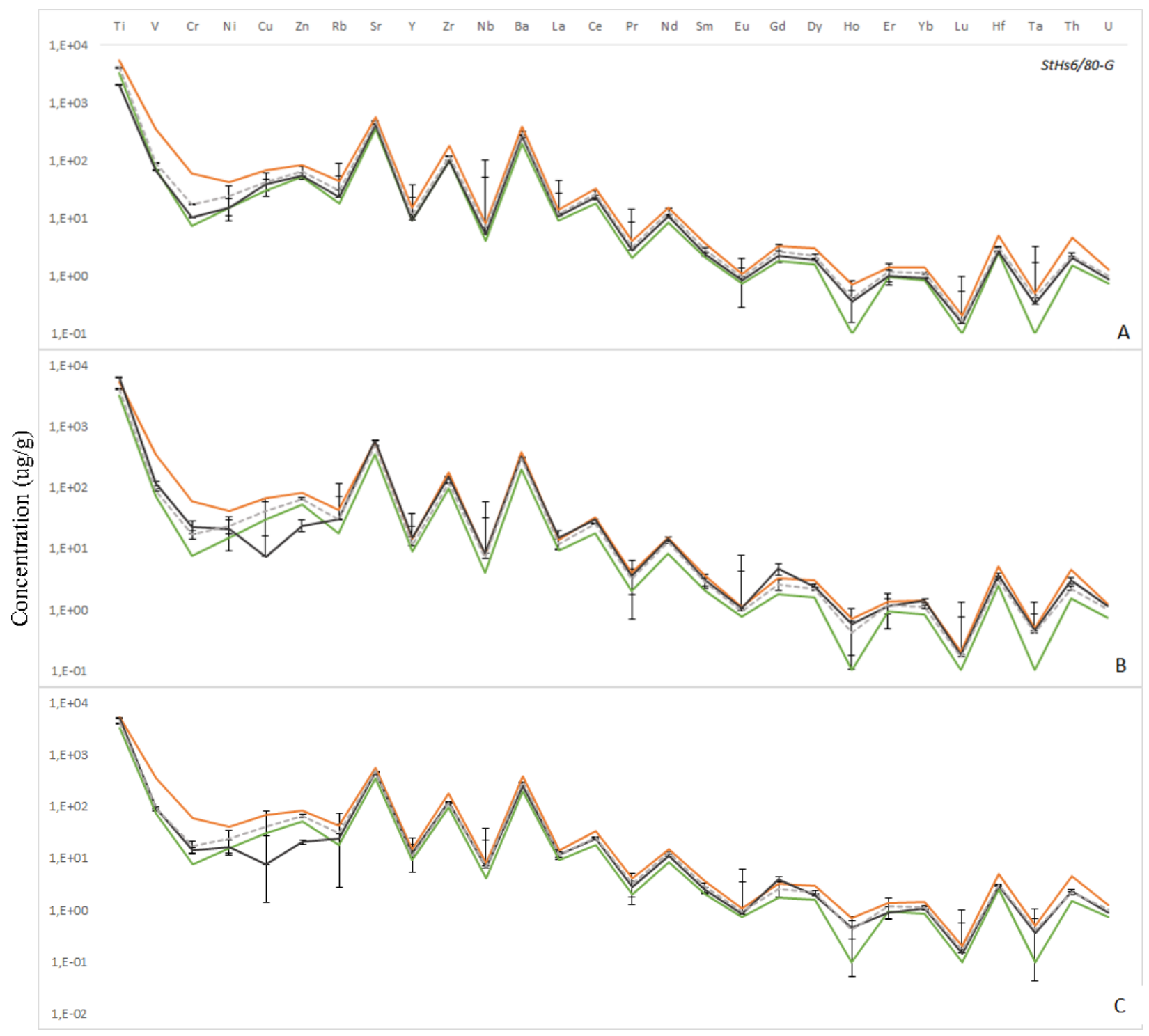

Figure 10. LA-ICP-MS trace element concentration of MPI-DING silicate glass StHs6/80-G (Andesite St. Helen) obtained in this study (solid black lines), trace element concentration corrected with RSF (dashed grey lines) and compared with the minimum and maximum values reported in the literature (green and orange solid lines, respectively). Error bars are two standard deviations $(2 \sigma)$ of the mean value. (A) Trace elements of StHs6/80-G using ${ }^{43} \mathrm{Ca}$ as IS and in-house spreadsheets reduction data. (B) Trace elements of StHs6/80-G using ${ }^{29} \mathrm{Si}$ as IS and software-reduced data. (C) Trace elements of StHs6/80-G using ${ }^{43} \mathrm{Ca}$ as IS and software reduction. Literature data were extracted from Jochum et al. (2005).

precision, but also being aware of how trace elements can respond differently during ablation (e.g., Rege et al. 2008, Jenner and O'Neill 2012). Once more analyses using the MPI-DING reference materials are routinely performed to validate our calibration, we will obtain more datapoints improving the statistical treatment of the data. Despite all the uncertainty factors identified so far, both the results reduced using in-house spreadsheets and those obtained using Glitter ${ }^{\circledR}$ software showed few results that need further correction and most of the lithophile trace elements were correctly determined.

To verify the accuracy of the data obtained with both reduction strategies, we compared our data with the values of reference materials, following Eggins (2003). This comparison can be expressed as the difference between our values and the correspondent reference values (RV) (Eq. 5):

$\left|x_{L A-I C P-M S}-x_{R V}\right|$
Korotev (1996) used the maximum uncertainty $\left(\sigma_{\max }\right)$ as the greatest uncertainty of the reference value $\left(\sigma_{\mathrm{RV}}\right)$ and the data obtained in the LA-ICP-MS analysis $\left(\sigma_{\text {LA-ICP-MS }}\right)$. A more rigorous tactic was presented by Eggins (2003), making a pooled uncertainty estimate with $\sigma_{\mathrm{RV}}$ and $\sigma_{\text {LA-ICP-MS }}$ (Eq. 6):

$\sigma_{\text {pooled }}=(1 / \sqrt{ } 2) \cdot\left(\sqrt{ }\left(\sigma_{R V}^{2}+\sigma_{L A-I C P-M S}^{2}\right)\right)$

and the test for agreement between the obtained data and the reference value at $95 \%$ confidence level is (Eq. 7):

$\left|x_{L A-I C P-M S}-x_{R V}\right|<1.96 \cdot \sigma_{\max }$

When using Equation 7, the concentration of the trace elements for $\mathrm{KL} 2-\mathrm{G}$ presented the following percentage of accuracy: $74 \%$ using spreadsheets, with $\mathrm{Zn}, \mathrm{Sr}$, and $\mathrm{Ho}$ as outliers; $92 \%$ using software reduction and both ${ }^{29} \mathrm{Si}$ and ${ }^{43} \mathrm{Ca}$ as IS, with $\mathrm{Cu}$ and $\mathrm{Zn}$ as outliers in both cases. For the 


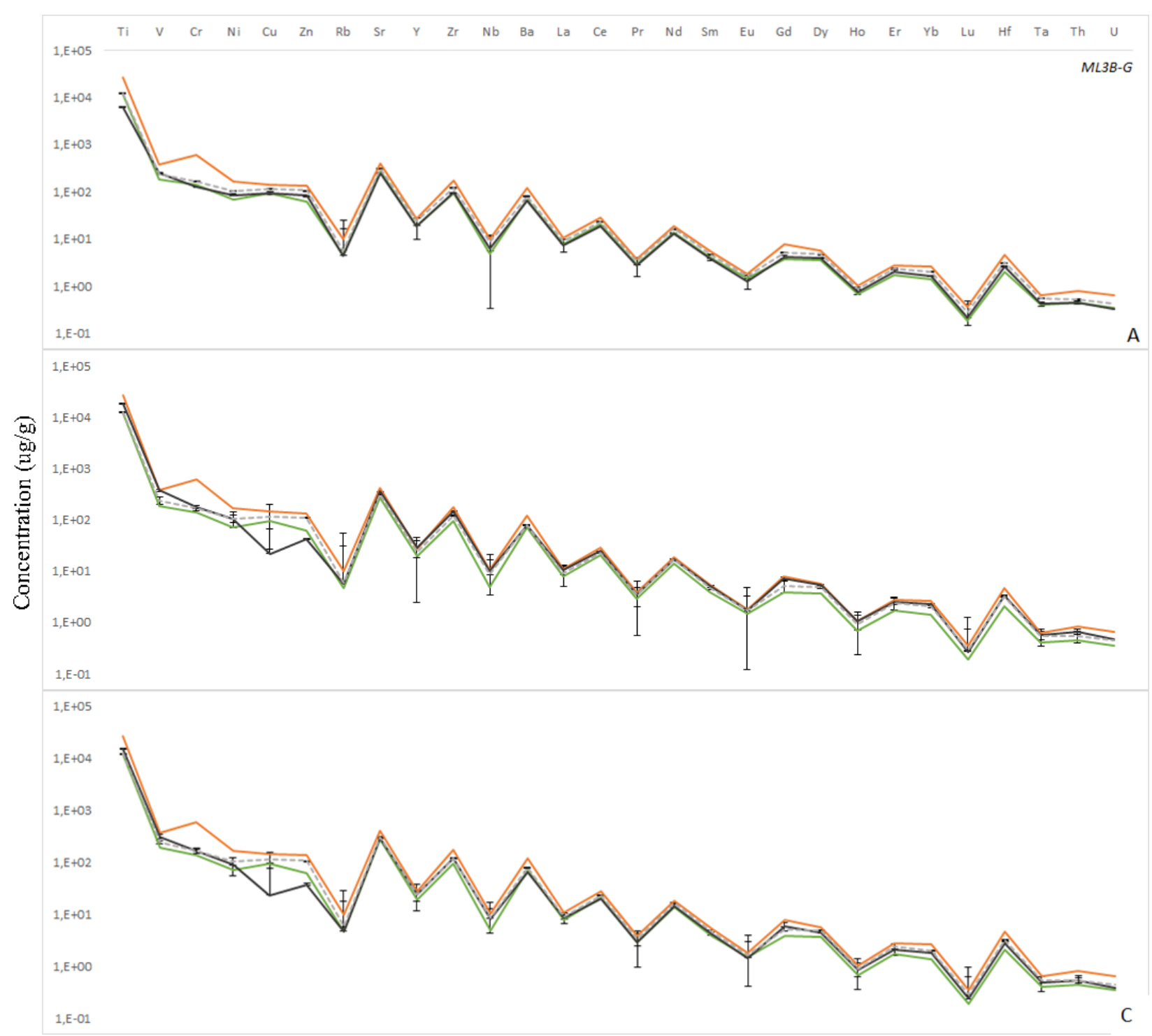

Figure 11. LA-ICP-MS trace element concentration of MPI-DING silicate glass ML3B-G (Mauna Loa basalt) obtained in this study (solid black lines), trace element concentration corrected with RSF (dashed grey lines) and compared with the minimum and maximum values reported in the literature (green and orange solid lines, respectively). Error bars are two standard deviations $(2 \sigma)$ of the mean value. (A) Trace elements of ML3B-G using ${ }^{43} \mathrm{Ca}$ as IS and in-house spreadsheets-reduced data. (B) Trace elements of ML3B-G using ${ }^{29} \mathrm{Si}$ as IS and software-reduced data. (C) Trace elements of ML3B-G using ${ }^{43} \mathrm{Ca}$ as IS and software reduction. Literature data were extracted from Jochum et al. (2005).

GOR132-G reference material, 91\% of the trace elements were correctly determined using spreadsheets, and the exceptions were $\mathrm{Zn}$ and $\mathrm{Rb}$. When using the software for data treatment and ${ }^{29} \mathrm{Si}$ and ${ }^{43} \mathrm{Ca}$ as IS, $85 \%$ and $89 \%$ of the elements were precisely measured, respectively, being V, Cr, $\mathrm{Cu}$, and $\mathrm{Zn}$ outliers with the first IS, and $\mathrm{Cu}$ and $\mathrm{Zn}$ outliers with ${ }^{43} \mathrm{Ca}$. The T1-G reference material had $100 \%$ of the trace elements correctly determined when using the spreadsheets, while $70 \%$ using the software and ${ }^{29} \mathrm{Si}$ as IS, with V, $\mathrm{Cu}, \mathrm{Sr}, \mathrm{Y}, \mathrm{La}, \mathrm{Ce}, \mathrm{Nd}$, and $\mathrm{Sm}$ as less accurate. On the other hand, also for the T1-G reference material, when ${ }^{43} \mathrm{Ca}$ was used as IS and when data was reduced using the software, $96 \%$ of the trace elements were accurately determined and the only exception was $\mathrm{Cu}$.

In the reference material ATHO-G, $100 \%$ of the trace elements were determined precisely using the spreadsheets, and the software and ${ }^{29} \mathrm{Si}$ as IS. When using ${ }^{43} \mathrm{Ca}$ as IS and the software, $96 \%$ of the elements were accurate in their results and $\mathrm{Cu}$ was the only exception. GOR128-G had $96 \%$ of the results correctly determined with the spreadsheets, with $\mathrm{Nb}$ as exception, $84 \%$ of results correct with the software and ${ }^{29} \mathrm{Si}$ as IS, with $\mathrm{Y}, \mathrm{Zn}, \mathrm{Cu}$, and $\mathrm{V}$ as outliers, and $92 \%$ with ${ }^{43} \mathrm{Ca}$ as IS and the software, with $\mathrm{Cu}$ and $\mathrm{Zn}$ as exceptions. The StHs6/80-G reference material presented $100 \%$ of the trace elements precisely determined with the spreadsheets, and the software with ${ }^{29} \mathrm{Si}$ as IS. When using the software and ${ }^{43} \mathrm{Ca}$ as IS, $96 \%$ of the elements had the aimed precision, and $\mathrm{Cu}$ was the exception. Finally, ML3B-G reference material had $81 \%$ of the analyzed trace elements determined with precision when using the spreadsheets, with the results for $\mathrm{Nb}, \mathrm{Pr}, \mathrm{Nd}, \mathrm{Sm}$, and Eu do not showing the same accuracy. When using the software and ${ }^{29} \mathrm{Si}$ as IS, only $\mathrm{Cu}$ presented imprecise results. When using ${ }^{43} \mathrm{Ca}$ as IS, $92 \%$ of trace elements were properly determined, and $\mathrm{Cu}$ and $\mathrm{Zn}$ were the outliers. 
Braz. J. Geol. (2021), 51(3): e20210018

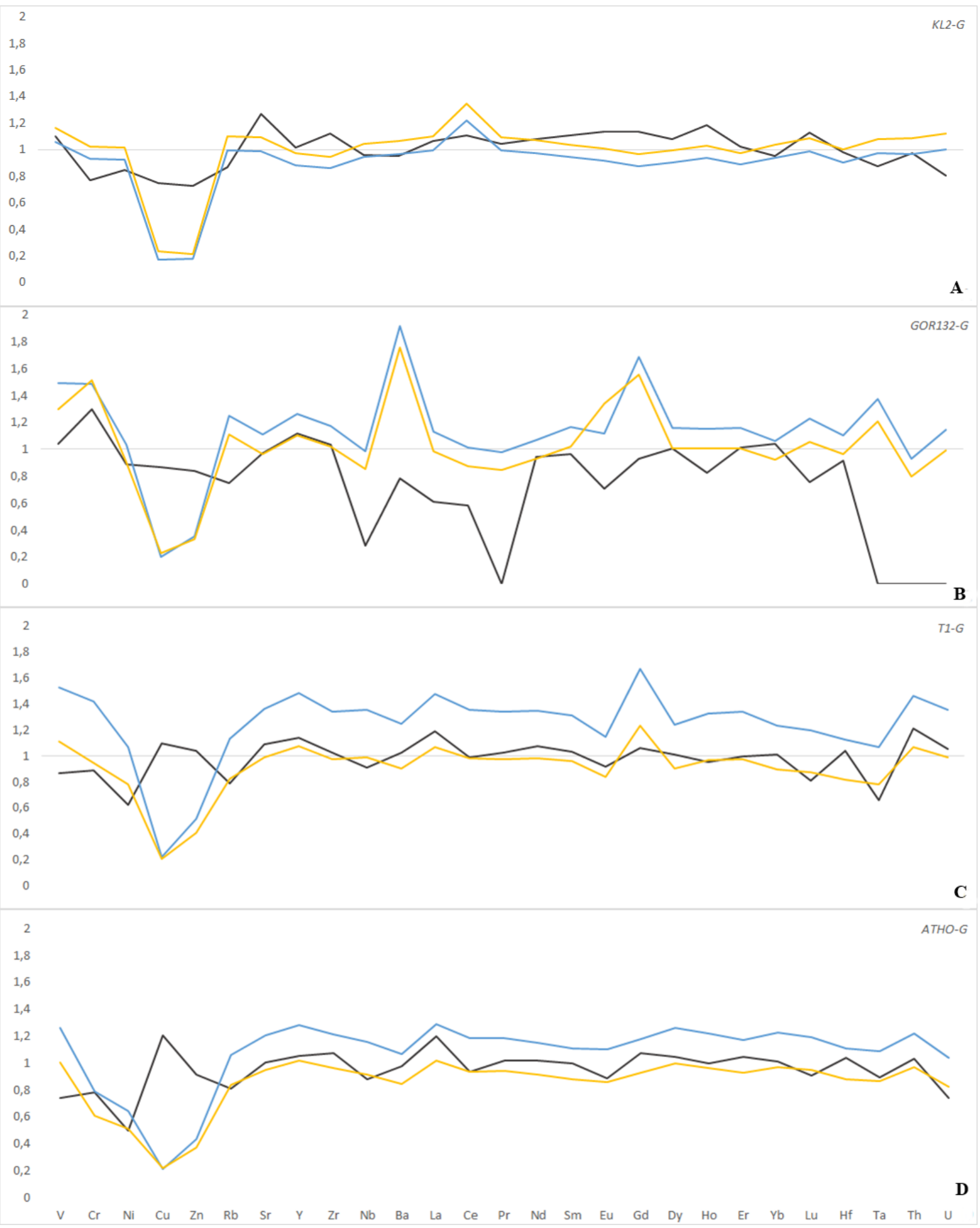

Figure 12. RSF values obtained for (A) KL2-G, (B) GOR132-G, (C) T1-G, and (D) ATHO-G. The values obtained with in-house spreadsheets reduction using ${ }^{43} \mathrm{Ca}$ as IS are represented by the black lines. The values obtained using software reduction are represented by blue lines ( ${ }^{29} \mathrm{Si}$ as IS) and yellow lines $\left({ }^{43} \mathrm{Ca}\right.$ as IS). A simple way to interpret the RSF chart is to consider the values close to one with low interferences of matrix match and fractionation, and small error value. The values much higher or lower than one are considered to have a high degree of interference or even a non-detectable element.

Such results corroborate the idea of multiple error sources, which has already been discussed, but also demonstrates the overall precision and accuracy of the method developed in our study, since most of the determinations had an accuracy above $90 \%$ and the few results with low precision can be corrected in the future. In this sense, the RSF values (Figs. 4 and 5) show the nature of the error obtained with the different ISs used and the different reduction strategies. RSF values of ca. $15 \%$ show that the value remains within the uncertainty of the method, possibly due to small fractionation and/or matrix match effects. The elements that have a RSF value about and/or over $20 \%$, represent a strong fractionation or a non-detectable element. It is important to note that most of this order of RSF value occurred using ${ }^{29} \mathrm{Si}$ as IS for reduction. This inference agrees 


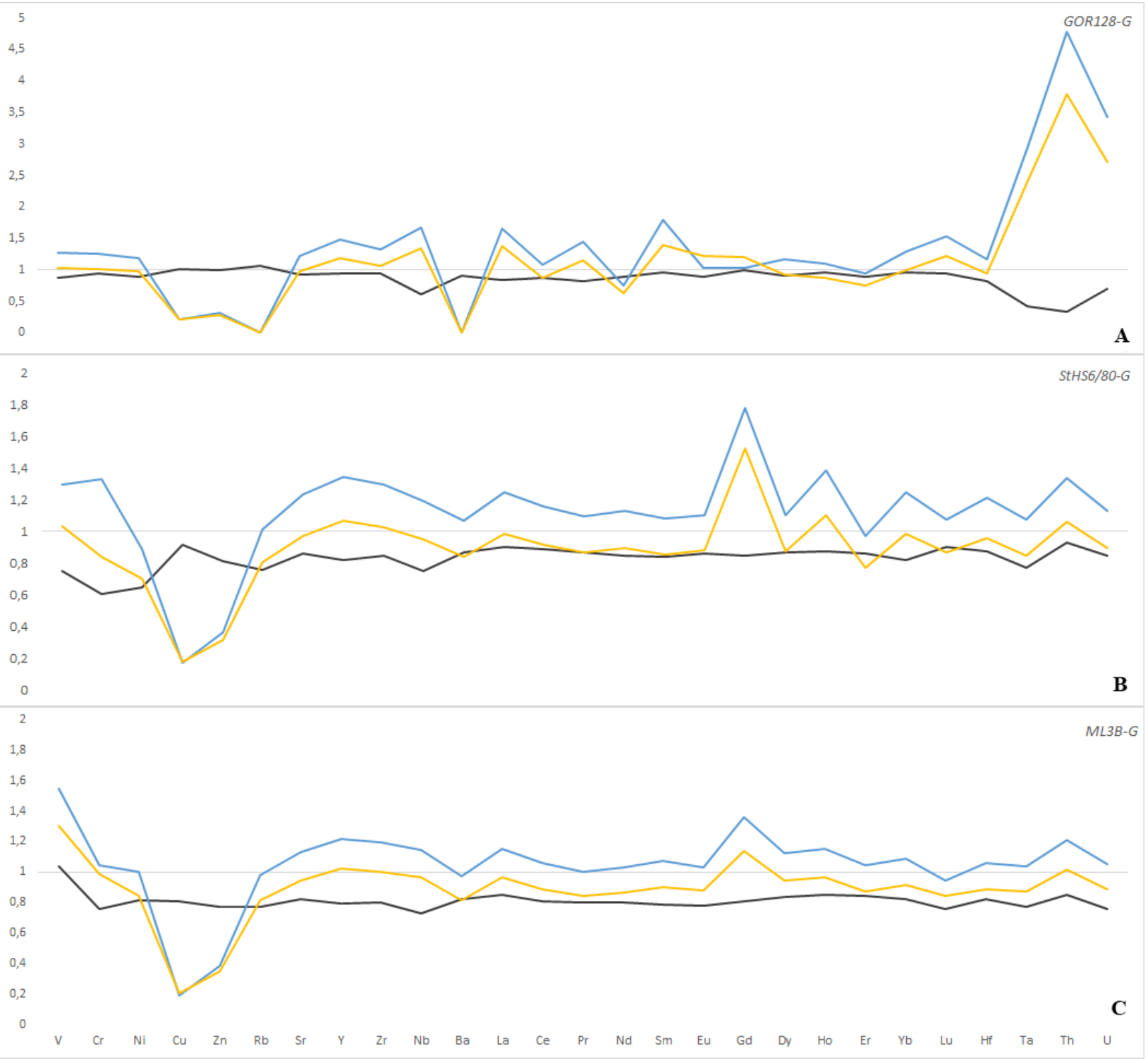

Figure 13. RSF values obtained for (A) GOR128-G, (B) StHs6/80-G, and (C) ML3B-G. The values obtained with in-house spreadsheets reduction using ${ }^{43} \mathrm{Ca}$ as IS are represented by the black lines. The values obtained using software reduction are represented by blue lines $\left({ }^{29} \mathrm{Si}\right.$ as IS) and yellow lines $\left({ }^{43} \mathrm{Ca}\right.$ as IS).

with the aforementioned literature (Jenner and O'Neill 2012, Jenner and Arevalo Jr. 2016) that associates the use of ${ }^{29} \mathrm{Si}$ as IS for reduction with higher fractionation and matrix match interference. We used the RSF values to correct the trace element data obtained, and the results are presented in Figures 3 to 9 . This strategy proved to be efficient so that the trace elements values detected for all MPI-DING glasses with the different reduction strategies and the different ISs used could be corrected to a value between the known maximum and minimum value in the literature (Willbold et al. 2003, Jochum et al. 2005, 2011, 2014). The use of the RSF value to evaluate the element trace data obtained and to correct the concentration values has proven to be a powerful tool in trace element quantification using the LA-ICP-MS method. In an analysis of a whole rock sample, the use of MPI-DING glass reference material with the same matrix, or an approximate matrix, and the RSF calculation allow for the identification of the matrix match and fractionation interferences. This factor can also be useful to identify the elements with a high error in quantification and correct their values properly in the future.

\section{CONCLUSION}

We presented a high-precision method for analyzing trace elements in silicate materials via LA-ICP-MS, using two different methods to manage the data: in-house reduction using a chart software and automated reduction using the Glitter ${ }^{\circledR}$ software. The NIST SRM 610/612 glasses were used as external standards, with two different elements as IS: ${ }^{43} \mathrm{Ca}$ (in chart and automated reduction) and ${ }^{29} \mathrm{Si}$ (in automated reduction only) (Jackson et al. 1992, Perkins et al. 1993, Jochum et al. 2011). When using the in-house spreadsheet reduction and ${ }^{43} \mathrm{Ca}$ as IS, this method had almost all values within error from the values reported in the literature for the MPI-DING glasses. The use of Glitter ${ }^{\circledR}$ software to process data reduction is a good alterative that yields an online and rapid response to quantify the data more effectively during the analyses. However, like any 
analytical method, the use of the software requires attention and adjustments to accurately assess background and intensity signals and avoid a false non-detected value. When using the in-house spreadsheets, the blank/background signals are acquired in a separate measure, without performing laser ablation (as describe in "Materials and methods: LA-ICP-MS"). This measure is easily subtracted from the analytic signal in the spreadsheet, and leaving no doubt as to the intensity of the blank signal. However, when using Glitter ${ }^{\circledR}$ reduction software, the blank/background signal is measured together with the sample analysis immediately before laser ablation. This makes the use of the reduction software advantageous over the manual spreadsheet. As the blank/background and the analytical signals are in the same measure, it is easy and quick to subtract one signal from the other in the software. However, the analyst must be careful to determine the end of the blank/background signal and the beginning of the analytic signal. Another advantage of the reduction software is that the results can be obtained almost instantly after the analysis. This avoids errors when transferring the data from the ICP-MS software to the spreadsheet and makes obtaining the result less laborious. Results obtained using ${ }^{43} \mathrm{Ca}$ and the reduction software were acceptable with a considerable number of trace elements identified properly. The same occurred when using ${ }^{29} \mathrm{Si}$ as IS, although the fractionation interference already registered compromise the quantification of trace elements in silicate glasses (Jenner and O'Neill 2012, Jenner and Arevalo Jr. 2016). Therefore, ${ }^{43} \mathrm{Ca}$ is the more appropriate element to use as IS to analyze trace elements in silicate glasses. This inference can be extended to mineral phases with silicate basis (e.g., clinopyroxene and apatite), considering the analogue matrix of the glasses and minerals. Nevertheless, this cannot be generalized indiscriminately, and parameters such as the spot size or IS chosen must be in accordance with the sample type, its size, and composition. The use of ${ }^{29} \mathrm{Si}$ as IS cannot be ruled out in future analysis of mineral phases. The use of NIST SRM
$610 / 612$ as calibration standard was adequate and the different matrixes did not interfere in the quantification analysis of the trace elements. It was possible to optimize the LA-ICP-MS system using a spot size above $40 \mu \mathrm{m}$ and detection limits in the magnitude of tens of $\mathrm{ng} / \mathrm{g}$ for good yield results. The use of a correction factor as the RSF has shown to be an effective approach to correct fractionation and matrix matched interferences when using the LA-ICP-MS method, and allowed for the correct evaluation of the trace elements with a measurable signal in this study. The RSF is of foremost importance to identify the source of errors during the analyses and correct the trace element contents that show evidence of strong fractionation. The geological glasses analyzed to validate this method showed results for major and minor elements in good accordance with the literature values, except for alkalis and manganese. The glasses are homogeneous, except for the GOR128-G komatiite that presented $\mathrm{Fe}-\mathrm{Cr}$ spinel crystals when analyzed in SEM. This spinifex structure is already known, but it had not yet been described in GOR128-G. These results demonstrate that the geological glasses can be used as external standards among the NIST-SRM standards in future analyses of trace elements in similar materials. Finally, the method developed can be widely used to determine whole-rock and mineral trace element geochemistry in research projects carried out in South America, when the correct analytical parameters are observed, being of great interest to the scientific community.

\section{ACKNOWLEDGEMENTS}

We would like to thank the technical and scientific staff at LGI and the Graduate Program in Geosciences (PPGGEO), Geosciences Institute, UFRGS, for their assistance and support. Klaus Jochum, Brigitte Stoll, and the Max-Planck-Institutfür Chemie (MPI) are thanked for having provided standard reference materials. This study has received funding from PETROBRAS Science and Technology development program (2017/00216-4).

\section{ARTICLE INFORMATION}

Manuscript ID: 20210018. Received on: 07/20/2020. Approved on: 08/03/2021.

A.W. performed the LA-ICP-MS analysis and treatment of trace element data, wrote the first draft of the manuscript, and prepared Figures 5 to 13; F.L. performed the LA-ICP-MS analysis and treatment of trace element data, wrote the first draft of the manuscript, improved the manuscript through corrections, and prepared Figures 1 to 4; C.P. contributed with suggestions in method development and validation, interpreted SEM data, and improved the manuscript through corrections and suggestions; R.C. contributed with suggestions in method development and validation, improved the manuscript through corrections and suggestions, and managed the financial contribution for conducting the analysis; M.G. performed the EPMA-WDS analysis and provided data for the major elements; M.S. contributed with the preparation of reference materials for LA-ICP-MS and improved the manuscript through corrections; D.C. performed the SEM analysis and provided the back-scattered images.

Competing interests: The authors declare no competing interests.

\section{REFERENCES}

Arevalo Jr. R. 2014. Laser Ablation ICP-MS and Laser Fluorination GSMS. In: Turekian K.K., Holland H.D. (Eds.). Treatise on Geochemistry. Amsterdam: Elsevier, v. 15, p. 425-444. https://doi.org/10.1016/ b978-0-08-095975-7.01432-7

Bagdassarov N.S., Dingwell D.B. 1992. A rheological investigation of Vesicular rhyolite. Journal of Volcanology and Geothermal Research, 50(3):307-322. https://doi.org/10.1016/0377-0273(92)90099-y

Bas M.J.L., Maitre R.W.L., Streckeisen A., Zanettin B. 1986. A chemical classification of volcanic rocks based on the total alkali-silica diagram. Journal of Petrology, 27(3):745-750. https://doi.org/10.1093/petrology/27.3.745
Becker J.S. 2007. Inorganic mass spectrometry: principles and applications. Chichester: John Wiley \& Sons, 514 p.

Becker J.S., Dietze H-J. 1998. Inorganic trace analysis by mass spectrometry. Spectrochimica Acta Part B: Atomic Spectroscopy, 53(11):1475-1506. https://doi.org/10.1016/s0584-8547(98)00110-4

Chan G.C.-Y., Chan W., Mao X., Russo R.E. 2000. Investigation of matrix effect on dry inductively coupled plasma conditions using laser ablation sampling. Spectrochimica Acta Part B: Atomic Spectroscopy, 55(3):221-235. https://doi.org/10.1016/s0584-8547(00)00140-3 
Chen Z. 1999. Inter-element fractionation and correction in laser ablation inductively coupled plasma mass spectrometry. Journal of Analytical Atomic Spectrometry, 14:1823-1828. https://doi.org/10.1039/a903272j

Chen L., Liu Y., Hu Z., Gao S., Zong K., Chen H. 2011. Accurate determinations of fifty-four major and trace elements in carbonate by LA-ICP-MS using normalization strategy of bulk components as 100\%. Chemical Geology, 284(3-4):283-295. https://doi.org/10.1016/j. chemgeo.2011.03.007

Colson R.O., Colson M.C., Nermoe M.K.B., Floden A.M., Hendrickson T.R. 2000. Effects of aluminum on $\mathrm{Cr}$ dimerization in silicate melts and implications for $\mathrm{Cr}$ partitioning and redox equilibria. Geochimica et Cosmochimica Acta, 64(3):527-543. https://doi.org/10.1016/ s0016-7037(99)00202-1

Dussubieux L., Golitko M., Gratuze B. (Eds.). 2016. Recent advances in laser ablation ICP-MS for archaeology. Berlin: Springer, 361 p. https://doi. org/10.1007/978-3-662-49894-1

Eggins S.M. 2003. Laser ablation ICP-MS analysis of geological materials prepared as lithium borate glasses. Geostandards and Geoanalytical Research, 27(2):147-162. https://doi.org/10.1111/j.1751-908x.2003.tb00642.x

Eggins S.M., Kinsley L.P.J., Shelley J.M.G. 1998. Deposition and element fractionation processes during atmospheric pressure laser sampling for analysis by ICP-MS. Applied Surface Science, 127-129:278-286. https://doi. org/10.1016/s0169-4332(97)00643-0

Eggins S.M., Shelley J.M.G. 2002. Compositional heterogeneity in NIST SRM 610-617 glasses. Geostandards and Geoanalytical Research, 26(3):269286. https://doi.org/10.1111/j.1751-908x.2002.tb00634.x

Eggins S.M., Woodhead J.D., Kinsley L.P.J., Mortimer G.E., Sylvester P., McCulloch M.T., Hergt J.M., Handler M.R. 1997. A simple method for the precise determination of $\geq 40$ trace elements in geological samples by ICPMS using enriched isotope internal standardization. Chemical Geology, 134(4):311-326. https://doi.org/10.1016/s0009-2541(96)00100-3

Frick D.A., Günther D. 2012. Fundamental studies on the ablation behavior of carbon in LA-ICP-MS with respect to the suitability as internal standard. Journal of Analytical Atomic Spectrometry, 27(8):1294-1303. https://doi. org/10.1039/c2ja30072a

Fryer B.J., Jackson S.E., Longerich H.P. 1995. The design, operation and role of the laser-ablation microprobe coupled with an inductively coupled plasma-mass spectrometer (LAM- ICP-MS) in the Earth sciences. Canadian Mineralogist, 33(2):303-312.

Gaboardi M., Humayun M. 2009. Elemental fractionation during LAICP-MS analysis of silicate glasses: implications for matrix-independent standardization. Journal of Analytical Atomic Spectrometry, 24(9):11881197. https://doi.org/10.1039/b900876d

Gill R. 2014. Chemical fundamentals of geology and environmental geoscience. $3^{\mathrm{a}}$ ed. Cambridge, John Wiley \& Sons, $288 \mathrm{p}$.

Griffin W.L., Powell W.J., Pearson N.J., O’Reilly S.Y. 2008. Glitter: Data reduction software for laser ablation ICP-MS. In: Sylvester P.J. (ed.). Laser ablation ICP-MS in the earth sciences: current practices and outstanding issues. Mineralogical Association of Canada Short Course Series, Short Course 40. Vancouver, B.C.: Mineralogical Association of Canada, p. 308-311.

Guillong M., Horn I., Günther D. 2003. A comparison of 266 nm, 213 nm and $193 \mathrm{~nm}$ produced from a single solid-state Nd:YAG laser for laser ablation ICP-MS. Journal of Analytical Atomic Spectrometry, 18(10):12241230. https://doi.org/10.1039/b305434a

Horn I., Von Blanckenburg F. 2007. Investigation on elemental and isotopic fractionation during $196 \mathrm{~nm}$ femtosecond laser ablation multiple collector inductively coupled plasma mass spectrometry. Spectrochimica Acta Part B: Atomic Spectroscopy, 62(4):410-422. https://doi.org/10.1016/j. sab.2007.03.034

Hutchinson D., McDonald I. 2008. Laser ablation ICP-MS study of platinum-group elements in sulphides from the Platreef at Turfspruit, northern limb of the Bushveld Complex, South Africa. Mineralium Deposita, 43:695-711. https://doi.org/10.1007/s00126-008-0190-6

Jackson S.E., Longerich H.P., Dunning G.R., Fryer B.J. 1992. The application of laser-ablation microprobe-inductively coupled plasma-mass spectrometry (LAM-ICP-MS) to in situ trace-element determinations in minerals. Canadian Mineralogist, 30(4):1049-1064.
Jenner F.E., Arevalo Jr. R.D. 2016. Major and trace element analysis of natural and experimental igneous systems using LA-ICP-MS. Elements, 12(5):311-316. https://doi.org/10.2113/gselements.12.5.311

Jenner F.E., O’Neill H.S.C. 2012. Major and trace analysis of basaltic glasses by laser-ablation ICP-MS. Geochemistry, Geophysics, Geosystems, 13(2):1-17. https://doi.org/10.1029/2011gc003890

Jochum K.P., Dingwell D.B., Rocholl A., Stoll B., Hofmann A.W., Becker S, Besmehn A., Bessette D., Dietze H.J., Dulski P., Erzinger J., Hellebrand E., Hoppe P., Horn I., Janssens K., Jenner G.A., Klein M., McDonough W.F., Maetz M., Mezger K., Münker C., Nikogosian I.K., Pickhardt C., Raczek I., Rhede D., Seufert H.M., Simakin S.G., Sobolev A.V., Spettel B., Straub S., Vincze L., Wallianos A., Weckwerth G., Weyer S., Wolf D., Zimmer M. 2000. The preparation and preliminary characterization of eight geological MPI-DING reference glasses for in-situ microanalysis. Geostandards and Geoanalytical Research, 24(1):87-133. https://doi.org/10.1111/j.1751-908x.2000.tb00590.x

Jochum K.P., Nohl U., Herwig K., Lammer E., Stoll B., Hofmann A.W. 2005. GeoREM: a new geochemical database for reference materials and isotopic standards. Geostandards and Geoanalytical Research, 29(3):333338. https://doi.org/10.1111/j.1751-908x.2005.tb00904.x

Jochum K.P., Scholz D., Stoll B., Weis U., Wilson S.A., Yang Q. Schwalb A., Börner N., Jacob D.E., Andreae M.O. 2012. Accurate trace element analysis of speleothems and biogenic calcium carbonates by LA-ICP-MS. Chemical Geology, 318-319:31-44. https://doi.org/10.1016/j.chemgeo.2012.05.009

Jochum K.P., Stoll B. 2008. Reference materials for elemental and isotopic analyses by LA-(MC)-ICP-MS: successes and outstanding needs. In: Sylvester P.J. (Ed.). Laser ablation ICP-MS in the Earth sciences: current practices and outstanding issues. Mineralogical Association of Canada Short Course Series, 40:147-168.

Jochum K.P., Stoll B., Herwig K., Willbold M. 2007. Validation of LAICP-MS trace element analysis of geological glasses using a new solid-state $193 \mathrm{~nm}$ Nd:YAG laser and matrix-matched calibration. Journal of Analytical Atomic Spectrometry, 22(2):112-121. https://doi.org/10.1039/b609547j

Jochum K.P., Stoll B., Weis U., Jacob D.E., Mertz-Kraus R., Andreae M.O. 2014. Non-matrix-matched calibration for the multi-element analysis of geological and environmental samples using $200 \mathrm{~nm}$ femtosecond LA-ICP-MS: a comparison with nanosecond lasers. Geostandards and Geoanalytical Research, 38(3):265-292. https://doi. org/10.1111/j.1751-908x.2014.12028.x

Jochum K.P., Weis U., Stoll B., Kuzmin D., Yang Q. Raczek I., Jacob D.E., Stracke A., Birbaum K., Frick D.A., Günther D., Enzweiler J. 2011. Determination of Reference Values for NIST SRM 610-617 Glasses Following ISO Guidelines. Geostandards and Geoanalytical Research, 35(4):397-429. https://doi.org/10.1111/j.1751-908x.2011.00120.x

Kamenetsky V.S., Gurenko A.A., Kerr A.C. 2010. Composition and temperature of komatiite melts from Gorgona Island, Colombia, constrained from olivine-hosted melt inclusions. Geology, 38(11):1003-1006. https:// doi.org/10.1130/g31143.1

Kelemen P.B., Shimizu N., Dunn T. 1993. Relative depletion of niobium in some arc magmas and the continental crust: partitioning of $\mathrm{K}, \mathrm{Nb}, \mathrm{La}$ and $\mathrm{Ce}$ during melt/rock reaction in the upper mantle. Earth and Planetary Science Letters, 120(3-4):111-134. https://doi. org/10.1016/0012-821X(93)90234-Z

Kempenaers L., Janssens K., Jochum K.P., Vincze L., Vekemans B., Somogyi A., Drakopoulos M., Adams F. 2003. Micro-heterogeneity study of trace elements in USGS, MPI-DING, NIST glass reference materials by means of synchrotron micro-XRF. Journal of Analytical Atomic Spectrometry, 18(4):350-357. https://doi.org/10.1039/b212196d

Kerr A.C., Marriner G.F., Arndt N.T., Tarney J., Nivia A., Saunders A.D., Duncan R.A. 1996. The petrogenesis of Gorgona komatiites, picrites and basalts: new field, petrographic and geochemical constraints. Lithos, 37(23):245-260. https://doi.org/10.1016/0024-4937(95)00039-9

Kimura J-I., Chang Q. 2012. Origin of the suppressed matrix effect for improved analytical performance in determination of major and trace elements in anhydrous silicate samples using $200 \mathrm{~nm}$ femtosecond laser ablation sector-field inductively coupled plasma mass spectrometry. Journal of Analytical Atomic Spectrometry, 27(9):1549-1559. https://doi. org/10.1039/c2ja10344c

Korotev R.L. 1996. A self-consistent compilation of elemental concentration data for 93 geochemical references samples. Geostandards and Geoanalytical Research, 20(2):217-245. https://doi.org/10.1111/j.1751-908X.1996.tb00185.x 
Kurosawa M., Jackson S.E., Sueno S. 2002. Trace element analysis of NIST SRM 614 and 616 glass reference materials by laser ablation microprobeinductively coupled plasma-mass spectrometry. Geostandards and Geoanalytical Research, 26(1):75-84. https://doi.org/10.1111/j.1751908x.2002.tb00625.x

Leitzke F.P., Fonseca R.O.C., Michely L.T., Sprung P., Münker C., Heuser A., Blanchard H. 2016. The effect of titanium on the partitioning behavior of high-field strength elements between silicates, oxides and lunar basaltic melts with applications to the origin of mare basalts. Chemical Geology, 440:219-238. https://doi.org/10.1016/j.chemgeo.2016.07.011

Leitzke F.P., Fonseca R.O.C., Sprung P., Mallmann G., Lagos M., Michely L.T., Münker C. 2017. Redox dependent behavior of molybdenum during magmatic processes in the terrestrial and lunar mantle: Implications for the Mo/W of the bulk silicate Moon. Earth and Planetary Science Letters, 474:503-515. https://doi.org/10.1016/j.eps1.2017.07.009

Liu Y., Hu Z., Gao S., Günther D., Xu J., Gao C., Chen H. 2008. In situ analysis of major and trace elements of anhydrous minerals by LA-ICP-MS without applying an internal standard. Chemical Geology, 257(1-2):34-43. https://doi.org/10.1016/j.chemgeo.2008.08.004

Longerich H.P., Jackson S.E., Günther D. 1996. Inter-laboratory note. Laser ablation inductively coupled plasma mass spectrometric transient signal data acquisition and analyte concentration calculation. Journal of Analytical Atomic Spectrometry, 11(9):899-904. https://doi.org/10.1039/ ja9961100899

Luo Y., Gao S., Longerich H.P., Günther D., Wunderli S., Yuan H-L., Liu $\mathrm{X}-\mathrm{M}$. 2007. The uncertainty budget of the multi-element analysis of glasses using LA-ICP-MS. Journal of Analytical Atomic Spectrometry, 22(2):122130. https://doi.org/10.1039/b608010c

Maniar P.D., Piccoli P.M. 1989. Tectonic discrimination of granitoids. Geological Society of America Bulletin, 101(5):635-643. https://doi. org/10.1130/0016-7606(1989) 101<0635:tdog>2.3.co;2

Münker C. 2000. The isotope and trace element budget of the Cambrian Devil River Arc System, New Zealand: identification of four source components. Journal of Petrology, 41 (6):759-788. https://doi.org/10.1093/ petrology/41.6.759

Orihashi Y., Hirata T. 2003. Rapid quantitative analysis of Y and REE abundances in XRF glass bead for selected GSJ reference rock standards using Nd-YAG 266nm UV laser ablation ICP-MS. Geochemical Journal, 37(3):401-412. https://doi.org/10.2343/geochemj.37.401

Outridge P.M., Doherty W., Gregoire D.C. 1997. Ablative and transport fractionation of trace elements during laser sampling of glass and copper. Spectrochimica Acta Part B: Atomic Spectroscopy, 52(14):2093-2102. https://doi.org/10.1016/s0584-8547(97)00112-2

Palme H., O’Neill H.S.C. 2014. Cosmochemical estimates of Mantle composition. In: Holland H.D., Turekian K.K. (Eds.). Treatise on geochemistry. 2a ed. Amsterdam: Elsevier, v. 3, p. 1-39. https://doi. org/10.1016/b978-0-08-095975-7.00201-1

Pearce J.A., Gale G.H. 1977. Identification of ore-deposition environment from trace-element geochemistry of associated igneous host rocks. Geological Society, London, Special Publications, 7:14-24. https://doi. org/10.1144/gsl.sp.1977.007.01.03

Pearce J.A., Harris N.B.W., Tindle A.G. 1984. Trace element discrimination diagrams for the tectonic interpretation of granitic rocks. Journal of Petrology, 25(4):956-983. https://doi.org/10.1093/petrology/25.4.956

Perkins W.T., Pearce N.J.G., Jeffries T.E. 1993. Laser ablation inductively coupled plasma mass spectrometry: A new technique for the determination of trace and ultra-trace elements in silicates. Geochimica et Cosmochimica Acta, 57(2):475-482. https://doi.org/10.1016/0016-7037(93)90447-5

Pfänder J.A., Münker C., Stracke A., Mezger K. 2007. Nb/Ta and Zr/Hf in ocean island basalts - Implications for crust-mantle differentiation and the fate of Niobium. Earth and Planetary Science Letters, 254(1-2):158-172. https://doi.org/10.1016/j.epsl.2006.11.027
Prowatke S., Klemme S. 2006. Trace element partitioning between apatite and silicate melts. Geochimica et Cosmochimica Acta, 70(17):4513-4527. https://doi.org/10.1016/j.gca.2006.06.162

Rege S., Griffin W.L., Kurat G., Jackson S.E., Pearson N.J., O’Reilly S.Y. 2008. Trace-element geochemistry of diamondite: Crystallization of diamond from kimberlite-carbonatite melts. Lithos, 106(1-2):39-54. https://doi. org/10.1016/j.lithos.2008.06.002

Regnery J., Stoll B., Jochum K.P. 2010. High-resolution LA-ICP-MS for accurate determination of low abundances of $\mathrm{K}, \mathrm{Sc}$ and other trace elements in geological samples. Geostandards and Geoanalytical Research, 34(1):1938. https://doi.org/10.1111/j.1751-908x.2009.00025.x

Reich M., Large R., Deditius A.P. 2017. New advances in trace element geochemistry of ore minerals and accessory phases. Ore Geology Reviews, 81 (Part 4):1215-1217. https://doi.org/10.1016/j.oregeorev.2016.10.020

Rocholl A. 1998. Major and trace element composition and homogeneity of microbeam reference material: basalt glass USGS BCR-2G. Geostandards and Geoanalytical Research, 22(1):33-45. https://doi.org/10.1111/j.1751908x.1998.tb00543.x

Russo R.E., Mao X., Gonzalez J.J., Zorba V.J., Yoo J. 2013. Laser ablation in analytical chemistry. Analytical Chemistry, 85(13):6162-6177. https://doi. org/10.1021/ac4005327

Sato K., Kawashita K. 2002. Espectrometria de massas em geologia isotópica. Geologia USP. Série Científica, 2(1):57-77. https://doi.org/10.5327/ s1519-874x2002000100007

Stalder R., Ulmer P., Thompson A., Günther D. 2001. High pressure fluids in the system $\mathrm{MgO}-\mathrm{SiO} 2-\mathrm{H} 2 \mathrm{O}$ under upper mantle conditions. Contributions to Mineralogy and Petrology, 140:607-618. https://doi.org/10.1007/ s004100000212

Stebbins J.F., McMillan P.F., Dingwell D.B. 1995. Structure, dynamics, and properties of silicate melts. In: Swainson I. (Ed.). Reviews in Mineralogy and Geochemistry. Washington: De Gruyter, n. 32, 632 p. https://doi. org/10.1515/9781501509384

Sylvester P.J., Jackson S.E. 2016. A brief history of laser ablation inductively coupled plasma mass spectrometry (LA-ICP-MS). Elements, 12(5):307310. https://doi.org/10.2113/gselements.12.5.307

Tanner M. 2010. Shorter signal for improved signal to noise ratio, the influence of Poisson distribution. Journal of Analytical Atomic Spectrometry, 25(3):405-407. https://doi.org/10.1039/b921077f

Thermo Finnigan Scientific. 2005. Element2 / Element XR - Operating Manual. Thermo Finnigan Scientific, 257 p.

Thiemens M.M., Sprung P., Fonseca R.O.C., Leitzke F.P., Münker C. 2019. Early Moon formation inferred from hafnium-tungsten systematics. Nature Geoscience, 12:696-700. https://doi.org/10.1038/s41561-019-0398-3

Thomas R. 2003. Practical guide to ICP-MS: a tutorial for beginners. New York: CRC, $342 \mathrm{p}$.

Whalen J.B., Currie K.L., Chappell B.W. 1987. A-type granites: geochemical characteristics, discrimination and petrogenesis. Contributions to Mineralogy and Petrology, 95:407-419. https://doi.org/10.1007/bf00402202

White W.M. 2013. Geochemistry. Oxford: Wiley, 701 p.

Willbold M., Jochum K.P., Raczek I., Amini M.A., Stoll B., Hofmann A.W. 2003. Validation of multi-element isotope dilution ICPMS for the analysis of basalts. Analytical and Bioanalytical Chemistry, 377:117-125. https://doi. org/10.1007/s00216-003-2037-4

Wu S., Karius V., Schmidt B.C., Simon K., Wörner G. 2018. Comparison of ultrafine powder pellet and flux-free fusion glass for bulk analysis of granitoids by laser ablation-inductively coupled plasma-mass spectrometry. Geostandards and Geoanalytical Research, 42(4):575-591. https://doi. org/10.1111/ggr.12230

Zhang L., Ren Z.-Y.Y., Xia X.-P.P., Yang Q. Hong L.-B., Wu D. 2019. In situ determination of trace elements in melt inclusions using laser ablation inductively coupled plasma sector field mass spectrometry. Rapid Communications in Mass Spectrometry, 33(4):361-370. https://doi. org $/ 10.1002 / \mathrm{rcm} .8359$ 